\title{
Synoptic-Dynamic and Airmass Characteristics Distinguishing Long- and Short-Duration Freezing Rain Events in the South-Central United States
}

\author{
Christopher D. McCray, ${ }^{\mathrm{a}}$ John R. Gyakum, ${ }^{\mathrm{a}}$ And Eyad H. Atallah ${ }^{\mathrm{b}}$

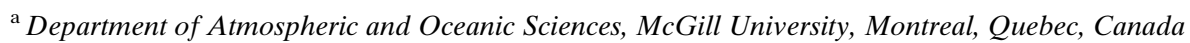 \\ ${ }^{\mathrm{b}}$ Department of Hydrology and Atmospheric Sciences, The University of Arizona, Tucson, Arizona
}

(Manuscript received 21 September 2020, in final form 29 January 2021)

\begin{abstract}
Though prolonged freezing rain events are rare, they can result in substantial damage when they occur. While freezing rain occurs less frequently in the south-central United States than in some regions of North America, a large number of extremely long-duration events lasting at least $18 \mathrm{~h}$ have been observed there. We explore the key synopticdynamic conditions that lead to these extreme events through a comparison with less severe short-duration events. We produce synoptic-dynamic composites and 7-day backward trajectories for parcels ending in the warm and cold layers for each event category. The extremely long-duration events are preferentially associated with a deeper and more stationary 500-hPa longwave trough centered over the southwestern United States at event onset. This trough supports sustained flow of warm, moist air from within the planetary boundary layer over the Gulf of Mexico northward into the warm layer. The short-duration cases are instead characterized by a more transient upper-level trough axis centered over the southcentral U.S. region at onset. Following event onset, rapid passage of the trough leads to quasigeostrophic forcing for descent and the advection of cold, dry air that erodes the warm layer and ends precipitation. While trajectories ending in the cold layer are very similar between the two categories, those ending in the warm layer have a longer history over the Gulf of Mexico in the extreme cases compared with the short-duration ones, resulting in warmer and moister onset warm layers.
\end{abstract}

KEYWORDS: Synoptic climatology; Synoptic-scale processes; Winter/cool season; Freezing precipitation; Mixed precipitation; Thermodynamics

\section{Introduction}

Freezing rain events are an especially disruptive winter weather phenomenon that can have substantial societal and economic impacts, ranging from hazardous road conditions to widespread tree damage and prolonged power outages. Several of these events have been documented in recent decades, from the United States and Canada (Rauber et al. 1994; Gyakum and Roebber 2001; Roebber and Gyakum 2003) to China (Zhou et al. 2011) and Romania (Andrei et al. 2019).

Freezing rain formation typically requires the coexistence of a near-surface cold $\left(\leq 0^{\circ} \mathrm{C}\right)$ layer and a warm $\left(>0^{\circ} \mathrm{C}\right)$ layer aloft. Snow forming above the warm layer falls into this layer, completely melts, and the resulting raindrops refreeze upon contact with the surface (e.g., Brooks 1920; Meisinger 1920). Freezing rain can also form via warm rain processes when raindrops (or more commonly drizzle drops) form via collisioncoalescence with ascent in a zone lacking active ice nuclei (e.g., with temperatures $\geq-10^{\circ} \mathrm{C}$ ) (Huffman and Norman 1988; Rauber et al. 2000).

The coexistence of the warm and cold layers is often aided by local terrain features that trap or channel cold air at the surface (Bernstein 2000; Rauber et al. 2001; Roebber and

McCray's current affiliation: Department of Earth and Atmospheric Sciences, Université du Québec à Montréal, Montreal, Québec, Canada.

Corresponding author: Christopher D. McCray, mccray. christopher_david@uqam.ca
Gyakum 2003). Climatological studies of freezing rain over North America (Rauber et al. 2001; Robbins and Cortinas 2002; Changnon 2003; Cortinas et al. 2004; McCray et al. 2019) have found local maxima in freezing rain frequency proximate to valleys or mountain ranges. Examples include the St. Lawrence River Valley in Quebec, Canada, east of the Appalachian Mountains in the southeastern United States, and in the Columbia basin region of the northwestern United States.

McCray et al. (2019) developed a climatology of longduration ( $\mathrm{LD}, \geq 6 \mathrm{~h}$ ) freezing rain events in the United States and Canada using surface observations from the NOAA Integrated Surface Database (Smith et al. 2011). Freezing rain and LD events are most common in the northeastern United States and southeastern Canada. The south-central United States (SCUS; Fig. 1), with more homogeneous terrain, experiences freezing rain less often but has a notable regional maximum in the frequency of the top $1 \%$ of events by duration (those lasting $\geq 18 \mathrm{~h}$ ). In this region, McCray et al. (2019) found that LD events begin with particularly deep warm layers and are commonly preceded by either liquid (32\% of cases) or no precipitation (43\%). The warm layer cools and dries by event end, resulting in freezing rain either ending or transitioning to freezing drizzle (32\% and $31 \%$ of events, respectively) or to snow/ice pellets $(25 \%)$. This evolution is in contrast to that of the other regions studied, where a snow/ice pellets to freezing rain to rain/drizzle evolution is the most common as the cold layer erodes and warm layer warms/deepens.

McCray et al. (2020) compared surface observations and thermodynamic profiles measured at the onset of LD events with those observed at short-duration (SD, 2-4h of freezing 


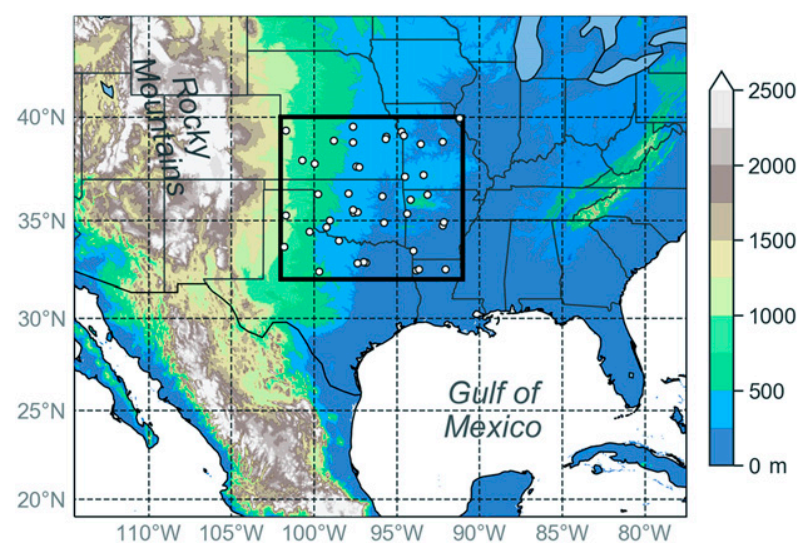

FIG. 1. Borders of (black box) and surface stations in (white dots) the south-central United States (SCUS) focus region. Surface elevation $(\mathrm{m})$ is shaded, with key geographic features discussed in the text labeled.

rain) event onset. In the SCUS, LD events begin with deeper and warmer warm layers aloft, with stronger warm-air advection (WAA) into the warm layer at LD onset than SD onset. A deeper, warmer warm layer with stronger WAA facilitates the layer's persistence despite cooling due to the extraction of latent heat of fusion during melting. Additionally, LD events begin with deeper cloud layers than SD events and stronger moisture advection into the warm layer. More saturated atmospheric profiles aloft prevent evaporative cooling from eroding the warm layer, and the preponderance of events that end in no precipitation or freezing drizzle suggests moisture characteristics aloft are important to event persistence.

The ubiquity of surface cold-air advection (CAA) throughout freezing rain events in the SCUS and the lack of substantial differences in onset cold-layer characteristics between SD and LD events suggest these conditions are not key to distinguishing LD from SD events. The key limiting factor to event duration over this region is a sufficiently warm/moist warm layer and deep cloud layer. Thus, synoptic-scale features conducive to the maintenance of warmer and moister conditions above the cold layer may lead to longer-duration events. For example, Mullens (2014) examined trajectories during two ice storm events in the southern Great Plains region and found that parcels ending in the warm layer during these events had a history in the marine planetary boundary layer (PBL) over the Gulf of Mexico. McCray et al. (2020) suggested that LD events in the SCUS were associated with synoptic patterns that allowed for sustained flow of warm, moist air from over the Gulf of Mexico into the warm layer aloft, preventing erosion or drying of the layer and allowing freezing rain to persist.

Synoptic-dynamic conditions leading to ice storms over regions overlapping the SCUS have been examined by Sanders et al. (2013) and Mullens et al. (2016b). Sanders et al. (2013) focused on major ice storms with at least $19.1 \mathrm{~mm}(0.75 \mathrm{in}$.) of ice accretion at one or more locations in their study area from 1979 to 2009. Their domain comprised 10 National Weather Service county warning areas centered on southern Missouri, just east of our SCUS box. They found that significant ice storms over this region were associated with a 500-hPa longwave trough axis centered over the western United States, with a surface anticyclone positioned over the northern plains. The cold front at the leading edge of this surface anticyclone becomes quasi-stationary to the south of the freezing rain area, while a low-level jet advects warm, moist air from over the Gulf of Mexico above the cold layer, sustaining the warm layer.

Mullens et al. (2016b) examined both snow and ice storms in the southern Great Plains region from 1993 to 2011, over an $8^{\circ} \times 10^{\circ}$ latitude-longitude box centered on Oklahoma. They performed an empirical orthogonal function analysis on the 500-hPa geopotential height fields associated with each event type, identifying five patterns for each. Each ice storm pattern exhibited a surface anticyclone over the northern/central Great Plains preceding event onset, most commonly with a quasi-stationary surface front within the region. A primary goal of their work was to compare patterns leading to a region of freezing precipitation with those producing only snow. To do this, short-duration/weak freezing rain events were either excluded entirely or grouped with snowstorms (Mullens et al. 2016b). Both Sanders et al. (2013) and Mullens et al. (2016b) explicitly excluded short-duration cases. Sanders et al. (2013) suggested the potential utility of comparing the conditions leading to less severe freezing rain events to the more severe ones examined in their study.

Our objective is to identify the synoptic-dynamic conditions distinguishing prolonged, potentially higher-impact freezing rain events from weaker, shorter-duration events in the SCUS. To achieve this, we compare the evolution of synoptic-scale features (e.g., geopotential height fields, quasigeostrophic (QG) forcing, surface cyclones and anticyclones) associated with the two event categories in section 3. We then compare the airmass origins and thermodynamic properties of parcels ending in the warm and cold layers for each event type through a trajectory analysis in section 4 .

\section{Data and methods}

\section{a. Freezing rain events}

We select freezing rain events from the 1979-2016 database of freezing rain observations developed in McCray et al. (2019) using surface reports from the NOAA Integrated Surface Database (Smith et al. 2011). We focus on the 43 surface stations in the SCUS box (Fig. 1), extending from $32^{\circ}$ to $40^{\circ} \mathrm{N}$ and from $91^{\circ}$ to $102^{\circ} \mathrm{W}$.

McCray et al. (2019) detected freezing rain events by first identifying consecutive hours of freezing rain at a given station, and then grouping any periods of freezing rain separated by $<24 \mathrm{~h}$ at the given station. Hourly freezing rain observations may contain mixtures with other precipitation types. The event onset is the hour of the first freezing rain observation within the event, while the event end time is the hour of the final freezing rain observation. The duration is the number of hourly freezing rain observations during the event. Details on the quality-control procedure used to identify stations in this dataset are discussed in McCray et al. (2019, section 2). 


\section{b. Identification of grouped cases}

Prior studies including composite analyses of freezing rain events in this region have focused on severe events. Identifying "weak" freezing rain cases is more challenging than identifying severe cases, as weaker cases are less likely to generate public reports of hazardous weather, such as those found in NOAA's Storm Data product used by Sanders et al. (2013) and Mullens et al. (2016b) to identify ice storm cases. Additionally, public measurements of ice accretion used in these studies often fail to specify whether the measurement represents radial thickness or depth on a horizontal surface, which is $\approx 2.5$ times larger (Ryerson and Ramsay 2007; Sanders and Barjenbruch 2016). Our use of event duration allows us to easily categorize events while avoiding these issues related to ice accretion measurements.

To compare conditions among SD and LD events, we first identify cases for compositing by grouping events that impacted multiple stations. We group any events among all SCUS stations that either occur simultaneously or within $6 \mathrm{~h}$ of each other (i.e., the start time of one event is $<6 \mathrm{~h}$ after the end time of another event in the SCUS box). To narrow the sample, and to avoid inclusion of spurious freezing rain events observed at only one station, we limit our analysis to grouped events in which freezing rain was observed at $\geq 4$ SCUS stations.

Following McCray et al. (2020), we identify SD grouped cases as those with a maximum duration among grouped events of 2-4 h. For example, three stations with a $1-\mathrm{h}$ freezing rain event and one station with a 2 -h event would be identified as an SD grouped case. The SCUS region is noteworthy for its relatively high frequency of the top $1 \%$ of events by duration ( $\geq 18$ h) (McCray et al. 2019; our Fig. 2). We are particularly interested in the synoptic-dynamic conditions that lead to these extreme events. We therefore create a new category of extremely long-duration (ELD) events, with grouped ELD cases defined as those with at least four stations observing a freezing rain event with at least one of duration $\geq 18 \mathrm{~h}$. We identify 43 SD and 42 ELD grouped cases meeting these criteria. Though shorter-duration freezing rain events are most common at individual stations (Cortinas et al. 2004; McCray et al. 2019, 2020), our ELD sample is enlarged due to its broader duration criteria and the fact that events of such extreme duration tend to affect multiple stations.

\section{c. Composite analysis}

Upon identifying grouped events, we produce synopticdynamic composites using the ERA-Interim dataset (Dee et al. 2011), with 6-hourly data starting in January 1979 on a $0.75^{\circ} \times 0.75^{\circ}$ horizontal grid and 60 vertical levels. While the ERA-Interim likely contains errors in near-surface temperature and wind fields, we primarily employ it for the synopticscale flow features upstream of the eventual ice storm region several days prior to event onset.

We define onset time for a grouped case as the median onset of all of the individual station events composing it, and center our composites on this time. This produces similar results to centering composites at the onset of the first event in the grouping but is less sensitive to outliers in onset times among

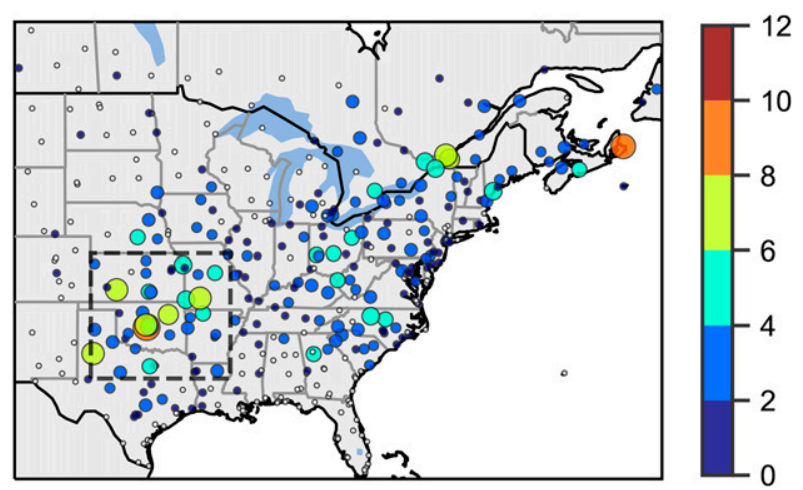

FIG. 2. Number of freezing rain events of duration $\geq 18 \mathrm{~h}$ observed at each station from 1979 to 2016. Modified from McCray et al. (2019, their Fig. 1d). The SCUS region is outlined in the black dashed box.

the individual stations. We composite various metrics at SD and ELD grouped event onset and in the days prior to and following onset. These metrics include surface cyclone and anticyclone life cycles, 500-hPa geopotential height, quasigeostrophic forcing, frontogenesis, and moisture transport.

To visualize the representativeness of the composites to the individual cases, we calculate the percentage of cases exhibiting anomalies of the same sign at each grid point and stipple regions in which this occurs for at least two-thirds of cases. This technique is analogous to stippling regions of statistically significant anomalies, with the benefit of being more physically intuitive and not suffering from issues related to the presentation of multiple hypothesis tests (e.g., Wilks 2016) or requiring the use of arbitrary $p$-value thresholds. ${ }^{1}$

Numerous tests were completed to identify the sensitivity of our results to various selections in this methodology. These included sensitivity to 1) criteria for event selection, such as increasing or decreasing the minimum number of stations necessary to include an event and changing the duration thresholds for the SD and ELD events, 2) selection of onset time for composites (i.e., using the median versus the firstevent onset), and 3) sensitivity to reanalysis dataset, for example CFSR (Saha et al. 2010) versus ERA-Interim. Though 1 and 2 produced slightly different quantitative differences between the event composites, qualitative results did not change based on any of these selections.

Multiple synoptic-dynamic settings may lead to freezing rain events in a given region. For example, Ressler et al. (2012) classified LD freezing rain events at Montreal into three categories based on the longitude of the $500-\mathrm{hPa}$ trough axis in each, while Mullens et al. (2016b) similarly classified southern Great Plains ice storms based on the $500-\mathrm{hPa}$ geopotential height field. Here, we aim not to identify every pattern leading to freezing rain events at each station, but instead to detect

\footnotetext{
${ }^{1}$ The presentation of results as statistically (in)significant based on thresholds of $p$ values is discouraged by the American Statistical Association (e.g., Wasserstein and Lazar 2016).
} 
SD onset $-72 \mathrm{~h}$

250-hPa Z (dam), winds $\left(\mathrm{m} \mathrm{s}^{-1}\right)$, u-wind anomalies $\left(\mathrm{m} \mathrm{s}^{-1}\right)$

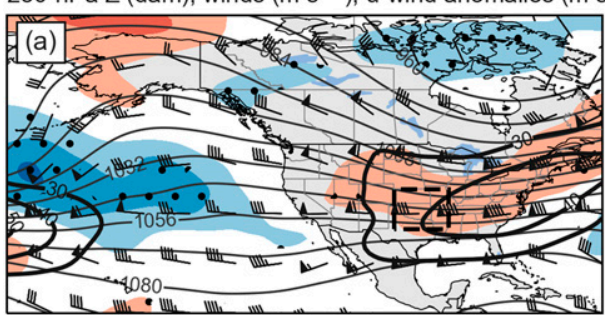

500-hPa Z (dam), Z anomalies (dam), 850-500-hPa $-\nabla \cdot$

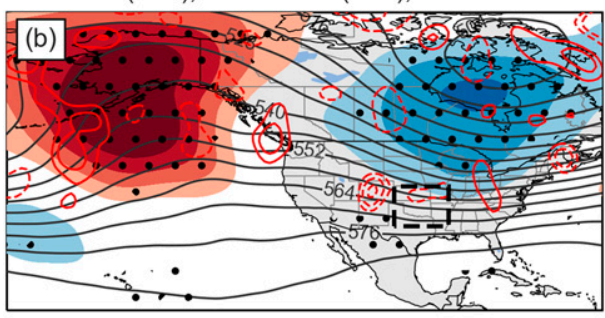

SLP (hPa), SLP anomalies (hPa), 1000-500-hPa thickness (dam)
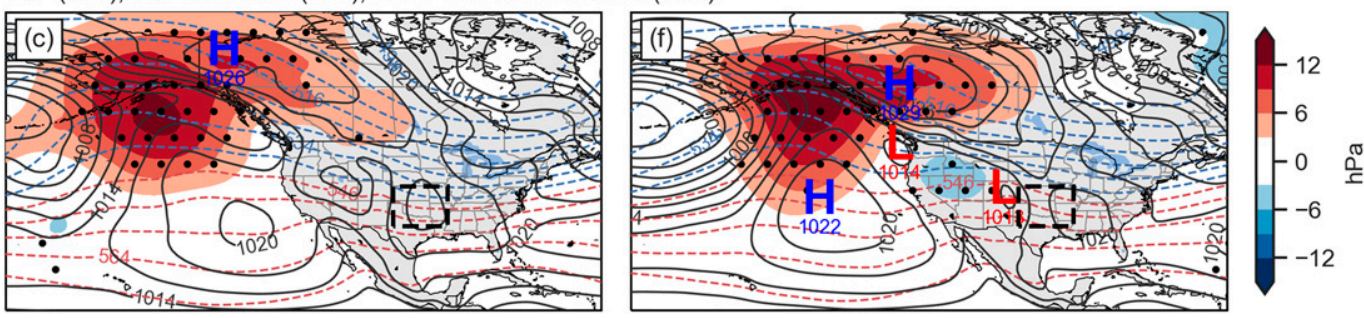

FIG. 3. Composites at $72 \mathrm{~h}$ prior to the onset of (left) SD and (right) ELD freezing rain events displaying (a),(c) 250-hPa geopotential heights (thin black contours, every 12 dam), winds (barbs, half barb $=2.5 \mathrm{~m} \mathrm{~s}^{-1}$, full barb = $5 \mathrm{~m} \mathrm{~s}^{-1}$, flag $=25 \mathrm{~m} \mathrm{~s}^{-1}$ ), wind speeds $\geq 30 \mathrm{~m} \mathrm{~s}^{-1}$ (thick black contours, every $10 \mathrm{~m} \mathrm{~s}^{-1}$ ), and zonal wind anomalies ( $\mathrm{m} \mathrm{s}^{-1}$, shaded); (b),(e) 500-hPa geopotential heights (black contours, every 6 dam) and height anomalies (shaded) and 850-500-hPa layer-averaged Q-vector convergence/divergence of magnitude $\geq 3 \times 10^{-19} \mathrm{~K} \mathrm{~m}^{-2} \mathrm{~s}^{-1}$ (red contours, every $2 \times 10^{-19} \mathrm{~K} \mathrm{~m}^{-2} \mathrm{~s}^{-1}$, dashed contours denote divergence); and (c),(f) sea level pressure (solid black contours, every $2 \mathrm{hPa}$ ), sea level pressure anomalies (shaded), and 1000-500-hPa thickness (dashed contours, every 4 dam). Stippling indicates grid points at which at least two-thirds of the cases composing the composite have anomalies of the same sign. The SCUS region is outlined in the black dashed box.

common features of these events and, most importantly, robust differences in patterns that lead to brief and prolonged events. Additionally, while the ice storm patterns examined by Mullens et al. (2016b) had important variations, they were substantially similar in terms of the large-scale flow regimes leading to them. We examined the individual events making up our composites and found coherent patterns associated with each event type.

\section{d. Trajectory analysis}

To examine the source regions and airmass properties of the parcels forming the warm and cold layers, we calculate trajectories using the Lagrangian analysis tool (LAGRANTO; Sprenger and Wernli 2015) with ERA-Interim data. At the median onset time of each event, we compute 7-day backward trajectories every $25 \mathrm{hPa}$ vertically from 1000 to $400 \mathrm{hPa}$ at equidistant grid points $(\Delta x=\Delta y=50 \mathrm{~km})$ in the SCUS domain (Fig. 1).

We identify criteria to select parcels representative of the warm and cold layers based on statistics of these layers from
McCray et al. (2019, 2020). Among freezing rain events in the SCUS with observed onset sounding data in McCray et al. (2020), the median level of the top (bottom) of the warm layer is $727(891) \mathrm{hPa}$, with the maximum temperature in the warm layer found at $834 \mathrm{hPa}$ in the median. In the cold layer, the minimum temperature is found $52 \mathrm{hPa}$ above the surface, while the top of the cold layer is found $75 \mathrm{hPa}$ above the surface in the median.

Corresponding to these values, we identify warm-layer level trajectories as those ending between 900 and $700 \mathrm{hPa}$ (inclusive) with parcel temperature $T>0^{\circ} \mathrm{C}$. We also require these trajectories to be at least $50 \mathrm{hPa}$ above the surface, as surface pressures $<900 \mathrm{hPa}$ are possible particularly in the western portion of the SCUS. Results are not highly sensitive to the choice of the range of layers. However, differences are present when comparing parcels ending at the lower part of this layer with those ending at the upper part. These differences will be discussed in section 4. We define cold-layer trajectories as those ending within $100 \mathrm{hPa}$ of the surface with a parcel temperature $\leq 0^{\circ} \mathrm{C}$. Cold-layer trajectory results were not 
SD onset $-48 \mathrm{~h}$

250-hPa Z (dam), winds $\left(\mathrm{m} \mathrm{s}^{-1}\right)$, u-wind anomalies $\left(\mathrm{m} \mathrm{s}^{-1}\right)$

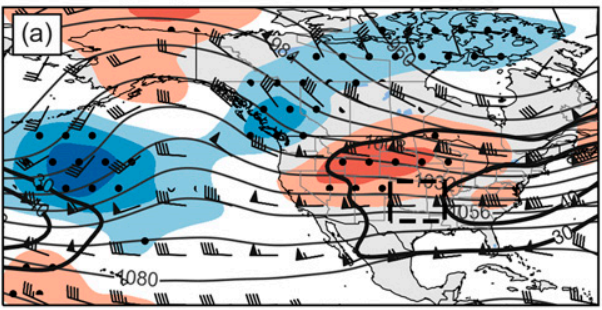

500-hPa Z (dam), Z anomalies (dam), 850-500-hPa $-\nabla$

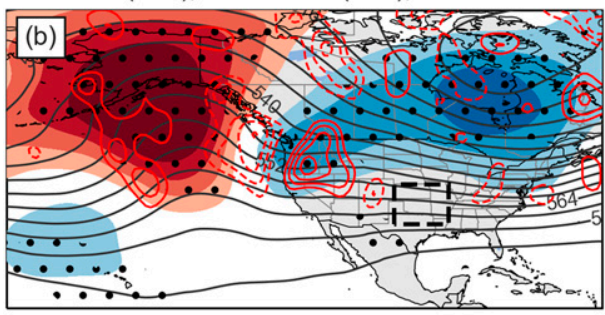

$\mathrm{SLP}(\mathrm{hPa})$, SLP anomalies (hPa), 1000-500-hPa thickness (dam)
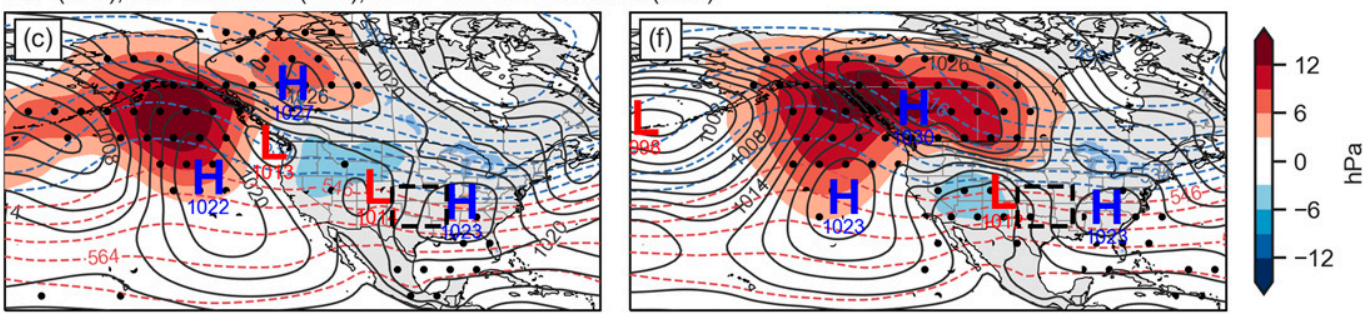

FIG. 4. As in Fig. 3, but at $48 \mathrm{~h}$ prior to event onset.
ELD onset $-48 \mathrm{~h}$
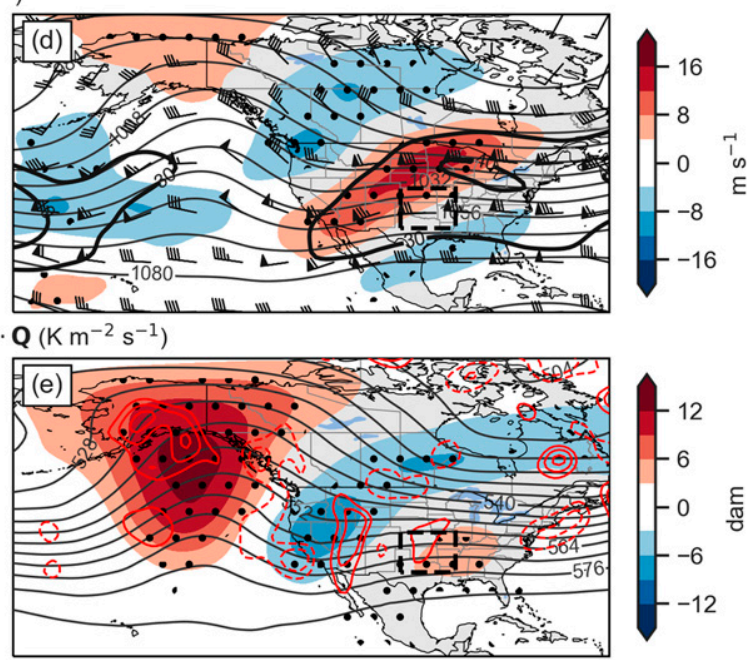

\section{$\frac{\sqrt{0}}{\mathrm{~T}}$}


SD onset $-24 \mathrm{~h}$

250-hPa Z (dam), winds $\left(\mathrm{m} \mathrm{s}^{-1}\right)$, u-wind anomalies $\left(\mathrm{m} \mathrm{s}^{-1}\right)$

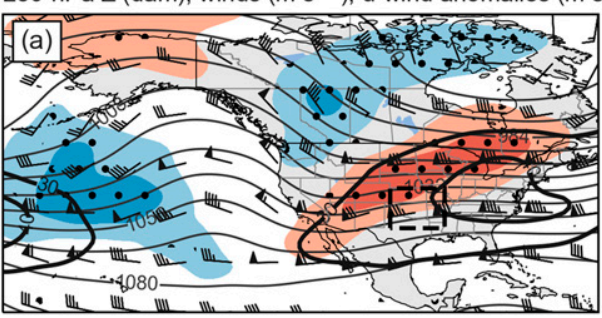

500-hPa Z (dam), Z anomalies (dam), $850-500-h P a-\nabla \cdot$

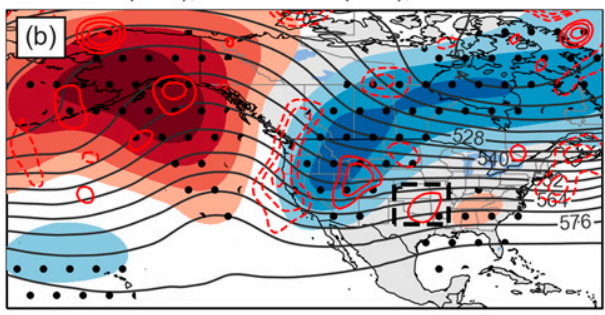

SLP (hPa), SLP anomalies (hPa), 1000-500-hPa thickness (dam)

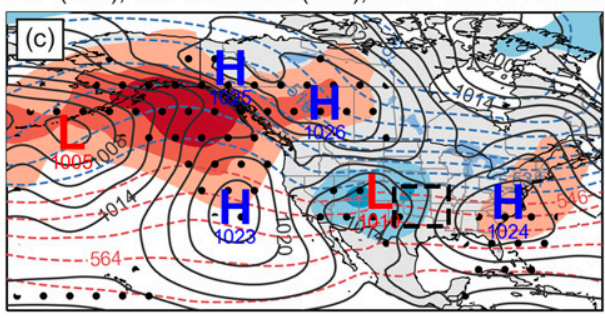

ELD onset $-24 \mathrm{~h}$

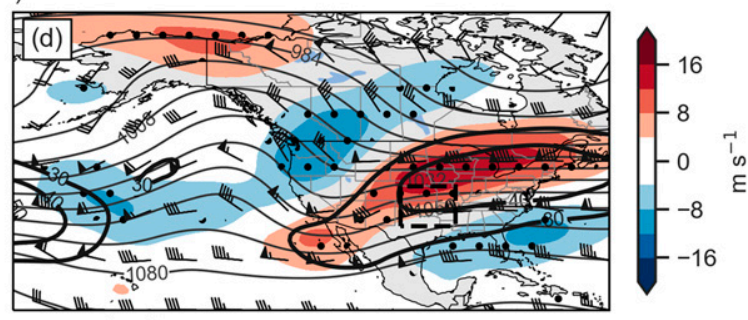

$\mathbf{Q}\left(\mathrm{K} \mathrm{m}^{-2} \mathrm{~s}^{-1}\right)$
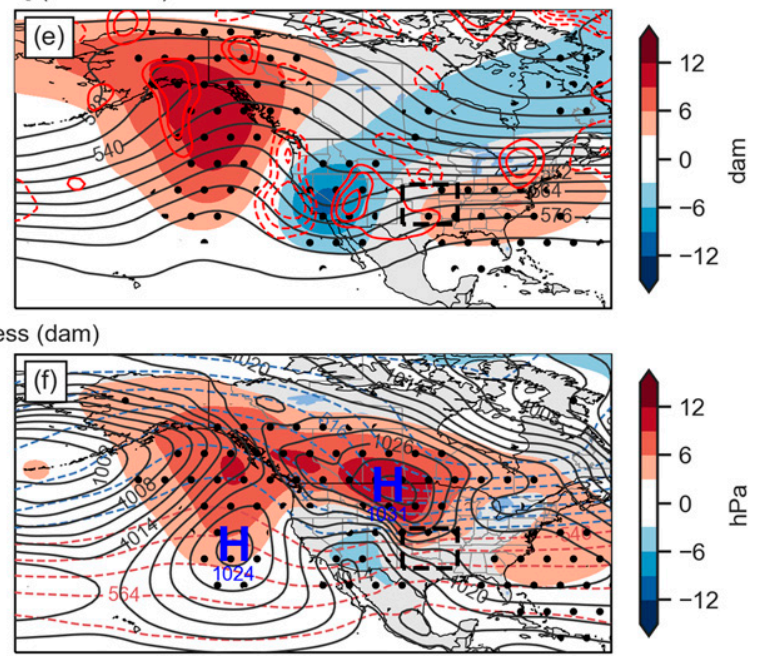

FIG. 5. As in Fig. 3, but at $24 \mathrm{~h}$ prior to event onset.

stretching from the western United States into central Canada (Figs. 4b,e). The anticyclone downstream of the ridge over western Canada has strengthened in both cases and has moved slightly southeastward (Figs. 4c,f). A large region of SLP anomalies $\geq+10 \mathrm{hPa}$ is present over western Canada in the ELD cases, while comparably strong anomalies are confined to the Gulf of Alaska in the SD composite. Positive SLP anomalies extend into the U.S. northern plains in the ELD composite, but are confined to western Canada in the SD composite (Figs. 4c,f). The placement of the ELD anticyclone results in a stronger baroclinic zone over the northern United States as evidenced by the stronger composite 250-hPa $u$-wind anomalies (Figs. 4a,d).

At $24 \mathrm{~h}$ prior to event onset, the ELD surface anticyclone has continued to travel southeastward into the northern plains, while the SD anticyclone remains over western Canada (Figs. 5c,f). The ELD anticyclone is favorably positioned in the confluent poleward entrance region of a strengthening $250-\mathrm{hPa}$ jet streak (Fig. 5d), with a weaker composite jet and less confluent flow evident in the vicinity of the SD anticyclone (Fig. 5a). This confluent flow is also evident at 500-hPa, with a split-flow pattern developing and a trough deepening over the southwestern United States (Fig. 5e). The SD longwave trough, with smaller amplitude and larger meridional extent, extends from the southwestern United States northeastward into Canada (Fig. 5b).

Downstream of these troughs, composite Q-vector convergence, forcing ascent, is collocated with negative SLP anomalies over the Rocky Mountains (Figs. 5c,f). The SD composite shows a stronger composite surface cyclone located northeastward of the ELD composite cyclone. In both composites, positive SLP anomalies are present off the U.S. East Coast in the equatorward jet exit region. The combination of these features results in southerly to southeasterly geostrophic near-surface flow into the SCUS region (Figs. 5c,f).

\section{b. Conditions at event onset}

At onset, the ELD composite strongly resembles those of Sanders et al. (2013) and Mullens et al. (2016b) for ice storms in this region. The surface anticyclones have traveled southeastward, with a 1031-hPa composite anticyclone centered over Minnesota at ELD onset and a weaker 1026-hPa composite anticyclone in the SD composite (Figs. 6c,f). The SD composite has a relatively small region of stippled grid points (indicating at least two-thirds of cases with positive SLP anomalies), compared with the ELD composite containing positive stippled SLP anomalies throughout eastern North America. The more coherent region of positive SLP anomalies in the SD composite is off the U.S. East Coast. In both cases, the combination of the anticyclones with cyclonic flow to the southwest of the SCUS results in southerly low-level geostrophic winds over the region at onset (Figs. 6c,f).

The differences evident at $-24 \mathrm{~h}$ have amplified by event onset. The ELD 500-hPa longwave trough is entirely confined to the southwestern United States (Fig. 6e), and in some cases 


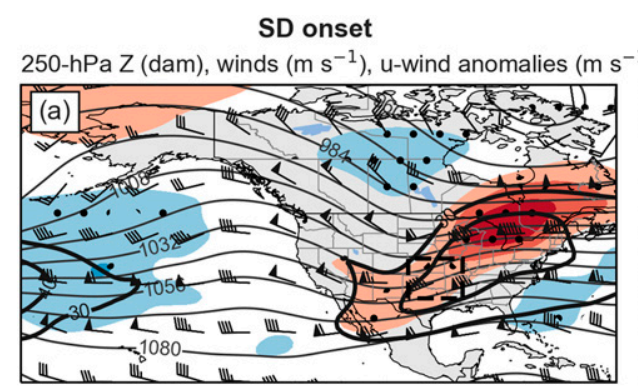

500-hPa Z (dam), Z anomalies (dam), 850-500-hPa $-\nabla$

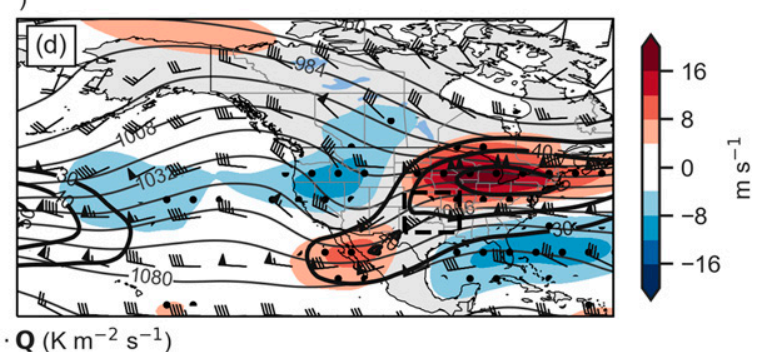

ELD onset
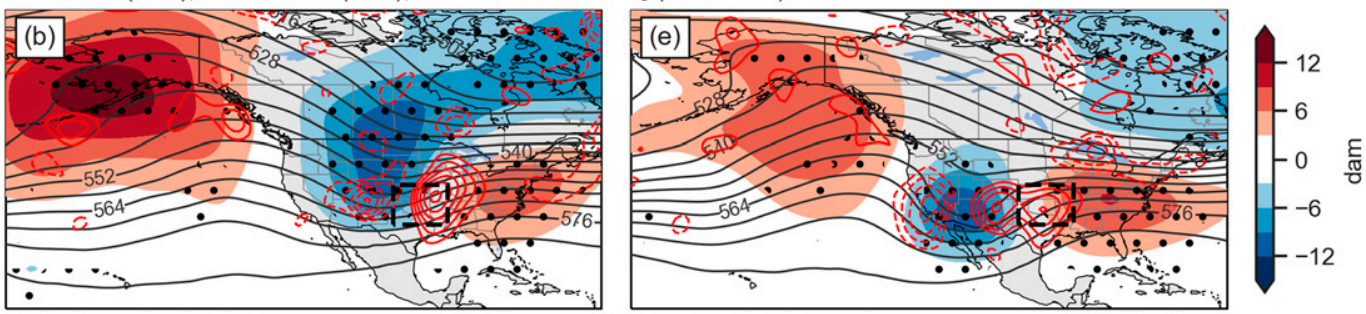

SLP (hPa), SLP anomalies (hPa), 1000-500-hPa thickness (dam)
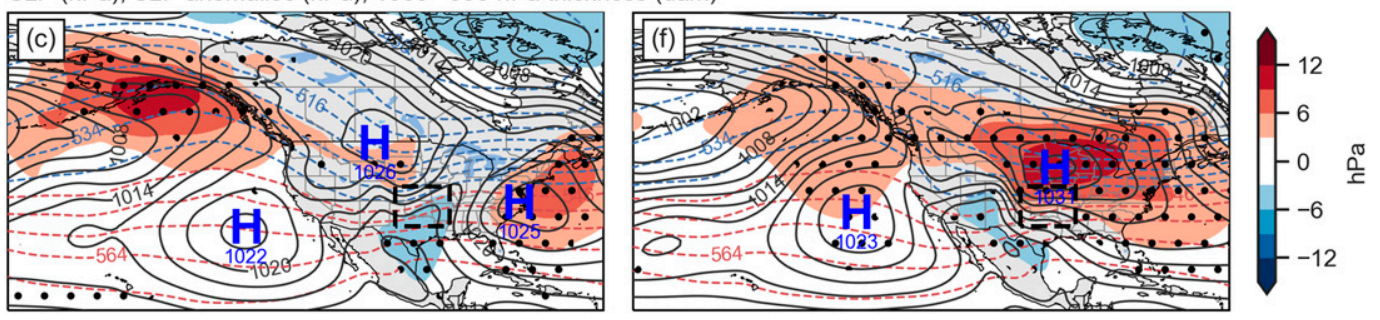

FIG. 6. As in Fig. 3, but at event onset.

becomes a cutoff low (not shown). The stronger ELD-composite split-flow pattern also enhances $250-\mathrm{hPa}$ confluence, helping to maintain the surface anticyclone with tropopause convergence (Figs. 6a,d). The SD composite trough, meanwhile, contains negative height anomalies extending from the U.S.-Mexico border northward into the Arctic (Fig. 6b). Both troughs are associated with a coherent couplet of QG forcing for ascent (descent), as evidenced by the Q-vector convergence (divergence) downstream (upstream) of the trough axes (Figs. 6b,e).

Notable differences appear in the QG-forcing structure. Though the SD-composite Q-vector convergence maximum is stronger, it is centered over the eastern portion of the SCUS box at onset, with Q-vector divergence present in the westernmost regions of the SCUS (Fig. 6b). In the ELD composite, the trough axis and its attendant upstream forcing for descent are positioned well to the west of the SCUS; the region of Q-vector convergence is much more zonally elongated (Fig. 6e).

We further examine the forcing for ascent by partitioning $\mathbf{Q}$ into its cross- and along-isentrope components $\mathbf{Q}_{n}$ and $\mathbf{Q}_{s}$. Convergence of $\mathbf{Q}_{s}$ represents synoptic-scale $\mathrm{QG}$ forcing for ascent via differential (cyclonic) geostrophic vorticity advection and geostrophic warm-air advection, while $\mathbf{Q}_{n}$ convergence is analogous to ascent due to geostrophic frontogenesis (e.g., Keyser et al. 1988; Milrad et al. 2014). At onset, the SD composite contains stronger convergence of both components of $\mathbf{Q}$, centered over the SCUS region's eastern portion
(Figs. 7a,b). While the ELD composite has weaker magnitudes of convergence of both components, $\mathbf{Q}_{n}$ convergence is present over a broad region from the SCUS eastward, indicating an east-west band of geostrophic frontogenesis (Fig. 7c). The $\mathbf{Q}_{s}$ convergence is maximized over the western part of the SCUS region, closer to the trough axis. Unlike the SD composite, no composite QG forcing for descent is present from either component in the SCUS box at onset.

Cold-frontal passage is evident in the $10-\mathrm{m}$ wind field at both SD and ELD onset, with surface frontogenesis bands present within the SCUS (Figs. 8c,f). Northerly winds exist north of the front, shifting to southerly to southeasterly south of the front. This surface flow orientation is consistent with past studies of freezing rain events in this region showing these events to be associated with the passage of an arctic cold front below warm air aloft (Sanders et al. 2013; Mullens 2014; Mullens et al. 2016b; McCray et al. 2019, 2020).

Variations in the orientation of the longwave troughs lead to important differences between the moisture fields at SD and ELD onset. Peak IVT magnitudes are $>400 \mathrm{~kg} \mathrm{~m}^{-1} \mathrm{~s}^{-1}$ in the SD composite and $>350 \mathrm{~kg} \mathrm{~m}^{-1} \mathrm{~s}^{-1}$ in the ELD composite, with IVT vectors demonstrating a clear moisture pathway from the subtropical Atlantic, over the Gulf of Mexico, and into the SCUS at both SD and ELD onset (Figs. 8a,d). However, peak IWV and IVT values are centered to the east of the SCUS at SD onset, but directly over the southern portion of the SCUS at ELD onset. Importantly, a maximum MFC of $>40 \mathrm{~mm} \mathrm{day}^{-1}$ is 

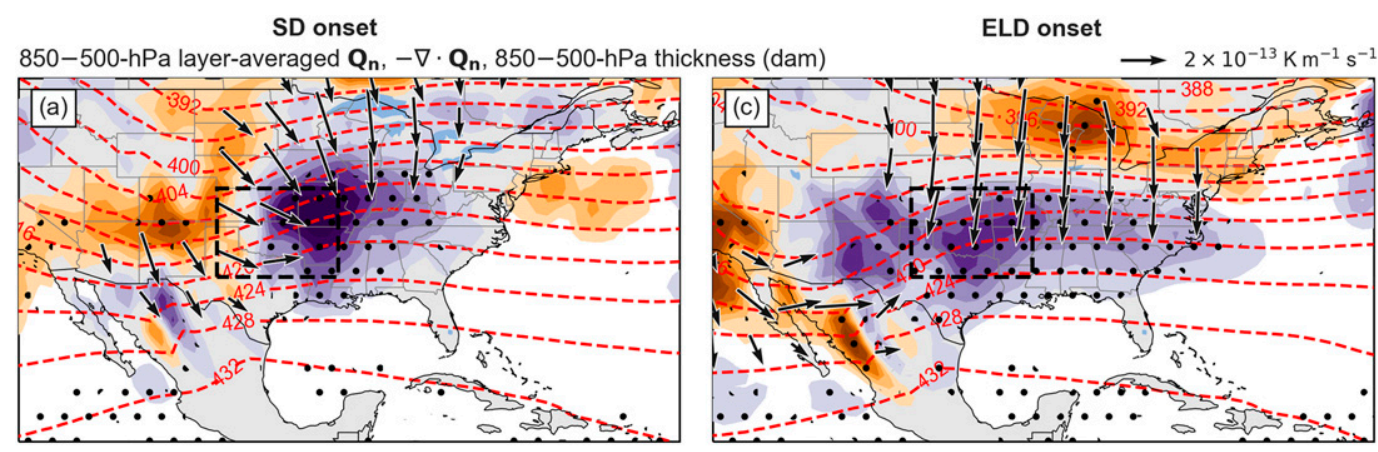

850-500-hPa layer-averaged $\mathbf{Q}_{\mathbf{s}},-\nabla \cdot \mathbf{Q}_{\mathbf{s}}, 850-500-\mathrm{hPa}$ thickness (dam)

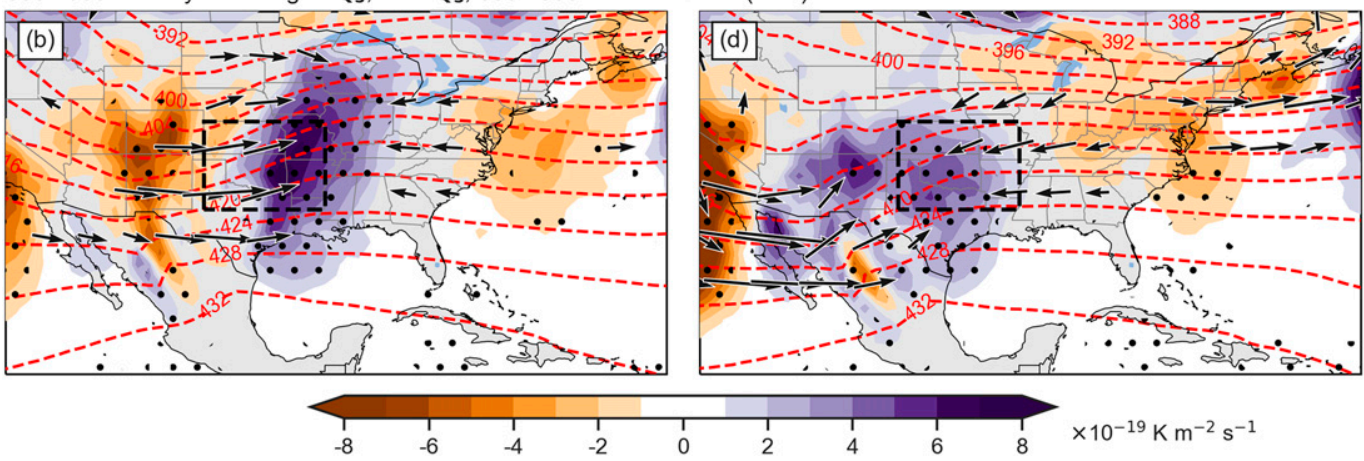

FIG. 7. Composite mean 850-500-hPa layer-averaged (a),(c) $\mathbf{Q}_{n}$ and(b),(d) $\mathbf{Q}_{s}$ components of the Q-vector at (left) SD and (right) ELD onset (vectors of magnitude $\geq 1 \times 10^{-13} \mathrm{~K} \mathrm{~m}^{-1} \mathrm{~s}^{-1}$ are plotted, with a reference vector at top right), convergence of each $\left(\mathrm{K} \mathrm{m}^{-2} \mathrm{~s}^{-1}\right.$, shaded with positive values indicating convergence), and 850-500-hPa thickness (red dashed contours, every $4 \mathrm{dam}$ ). Stippling indicates locations where the sign of the plotted convergence is the same for at least two-thirds of the cases composing the composite.

centered in the middle of the SCUS at ELD onset, compared with a maximum of $\approx 20 \mathrm{~mm} \mathrm{day}^{-1}$ positioned to the east of the SCUS at SD onset.

Sanders et al. (2013) and Mullens (2014) discussed the role of isentropic ascent of warm, moist air from the Gulf of Mexico in developing the warm layer aloft during ice storms in the SCUS region. For SD and ELD cases we analyze the 298-K isentropic surface, positioned in the SCUS at a vertical level (800-850-hPa) typically within the warm layer (Figs. 8b,e). In the ELD composite, strong isentropic ascent is present as indicated by the strong southerly winds of up to $30 \mathrm{~m} \mathrm{~s}^{-1}$ perpendicular to the pressure contours (Fig. 8e). The SD composite also suggests isentropic ascent, but winds and the pressure gradient are both weaker, with maximum winds of $\approx 15 \mathrm{~m} \mathrm{~s}^{-1}$ over the SCUS (Fig. 8b).

Consistent with the analysis of IVT, MFC, and IWV (Figs. 8a,d), the ELD onset composite also suggests strong 298-K moisture advection into the SCUS, with winds advecting moist air (water vapor mixing ratios $\geq 14 \mathrm{~g} \mathrm{~kg}^{-1}$ ) from the Gulf of Mexico surface layer northward. The SD composite suggests 298-K parcel trajectories from the Mexican Plateau, with southwesterly winds advecting drier air $\left(w \approx 4-8 \mathrm{~g} \mathrm{~kg}^{-1}\right)$ relative to the ELD composite.

McCray et al. (2020) found that SD events in the SCUS begin with cooler warm layers and drier atmospheric profiles than LD events, with the SD cases' warm layers rapidly eroding. The differences in moisture transport and the wind field in the warm layer appear to explain these findings. For example, the observed wind profiles examined in McCray et al. (2020) showed southerly to southeasterly flow at the base of the warm layer at LD event onset, but southwesterly flow at this level at SD onset (Figs. 8b,e). The southerly flow from the Gulf of Mexico into the ELD warm layer likely advects warmer, moister air into that layer than in the SD cases, in which flow is predominantly from over land. The disconnection of the flow field from the warm, moist air of the Gulf of Mexico appears to be the key difference in the synoptic-dynamic features resulting in erosion of the warm layer. This will be examined further in the trajectory analysis in section 4 .

\section{c. Conditions $12 \mathrm{~h}$ after onset}

The ELD composite's more compact, higher-amplitude trough progresses eastward more slowly than the lower-amplitude SD trough, and the ELD composite fields change only slightly in the $12 \mathrm{~h}$ following onset. At $+12 \mathrm{~h}$ after ELD onset, the 250 -hPa jet streak remains centered over the Great Lakes region, while the SD jet streak has shifted eastward over Quebec (Figs. 9a,d). The 500-hPa longwave trough remains centered over the southwestern United States in the ELD composite, with associated Q-vector convergence over the SCUS (Fig. 9e).

Composite values of both $\mathbf{Q}_{n}$ and $\mathbf{Q}_{s}$ convergence remain over the region (Figs. 10c,d). The surface anticyclone has traveled slowly eastward, weakening by $2 \mathrm{hPa}$, with positive SLP anomalies remaining over much of the northern and 
SD onset

IVT $\left(\mathrm{kg} \mathrm{m}^{-1} \mathrm{~s}^{-1}\right), \operatorname{MFC}(\mathrm{mm}), \operatorname{IWV}(\mathrm{mm})$

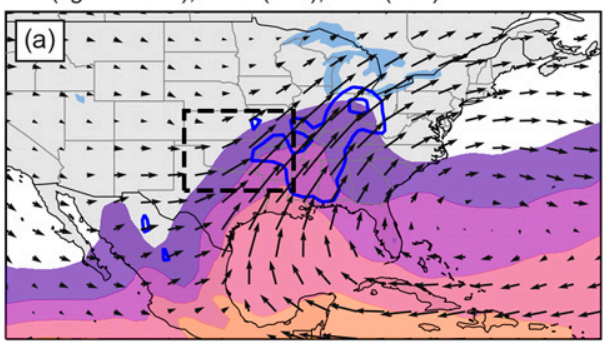

298-K pressure $(\mathrm{hPa})$, winds $\left(\mathrm{m} \mathrm{s}^{-1}\right)$, mixing ratio $\left(\mathrm{g} \mathrm{kg}^{-1}\right)$

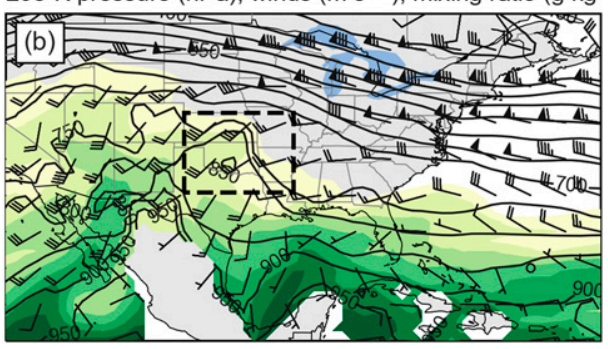

$\mathrm{SLP}(\mathrm{hPa}), 2-\mathrm{m} \theta(\mathrm{K}), 10-\mathrm{m}$ winds $\left(\mathrm{m} \mathrm{s}^{-1}\right)$, sfc. frontogenesis $\left[\mathrm{K}(100 \mathrm{~km})^{-1}(3 \mathrm{~h})^{-1}\right]$
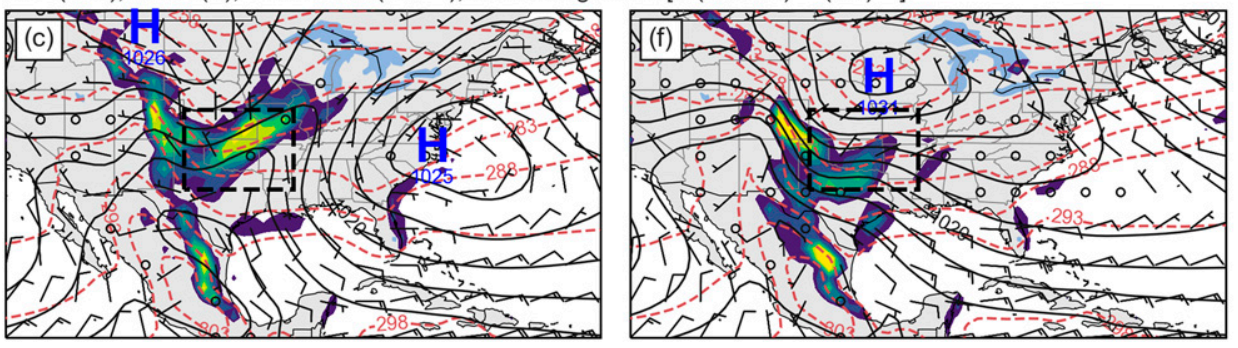

ELD onset
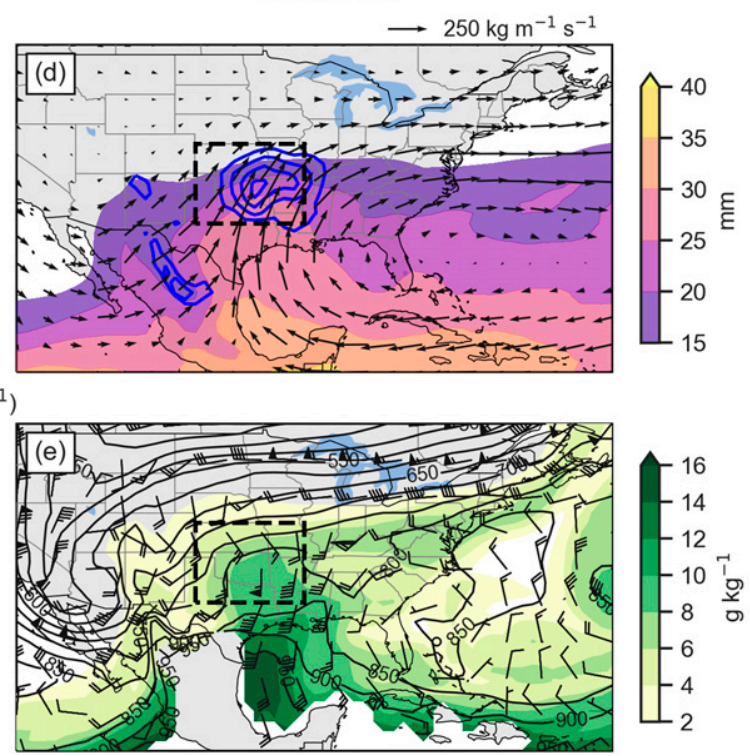

FIG. 8. Composites at (left) SD and (right) ELD event onset: (a),(d) composite mean 1000-300-hPa integrated vapor transport (vectors, with a reference vector at top right), moisture flux convergence $\geq 10 \mathrm{~mm} \mathrm{day}^{-1}$ (blue contours, every $5 \mathrm{~mm} \mathrm{day}^{-1}$ ), and integrated water vapor (shaded); (b),(e) pressure (solid contours, every $50 \mathrm{hPa}$ ), winds (barbs, as in Fig. 3), and mixing ratio ( $\mathrm{g} \mathrm{kg}^{-1}$, shaded) on the 298-K isentropic surface; and (c),(f) sea level pressure (contoured, every $2 \mathrm{hPa}$ ), $2-\mathrm{m}$ potential temperature (K, red contours, every $5 \mathrm{~K}$ ), and surface frontogenesis $\left[\mathrm{K}(100 \mathrm{~km})^{-1}(3 \mathrm{~h})^{-1}\right.$, shaded] calculated using 2-m potential temperature and $10-\mathrm{m}$ winds.

eastern United States (Fig. 9f). Surface frontogenesis remains over the southern portion of the SCUS (Fig. 11f), and the flow of moist air northward into the region continues with a region of MFC $\geq 20 \mathrm{~mm} \mathrm{day}^{-1}$ over the eastern part of the SCUS.

The SD composite indicates the longwave trough axis has traversed most of the SCUS. Behind the trough, Q-vector divergence indicative of QG forcing for descent is present over most of the region (Fig. 9b), with composite divergence of both $\mathbf{Q}_{n}$ and $\mathbf{Q}_{s}$ (Figs. 10a,b). This suggests descent both from frontolysis and differential anticyclonic vorticity advection associated with the trough as well as low-level CAA following the cold-frontal passage. Indeed, $850-\mathrm{hPa}$ CAA is present over most of the SCUS at this time in the SD composite, while WAA persists in the ELD composite (not shown).

Positive SD-composite SLP anomalies are confined to the western Atlantic, with the surface anticyclone over the plains now located just north of the SCUS (Fig. 9c). The surface cold front has progressed southward over the Gulf Coast as indicated by the $10-\mathrm{m}$ wind field (Fig. 11c). Consequently, in contrast with the ELD composite, SD-composite surface cold frontogenesis is nearly absent from the SCUS (Figs. 11c,f).

The connection between the warm layer and the Gulf of Mexico has been effectively eliminated by $12 \mathrm{~h}$ after SD onset, with $\mathrm{MFC} \geq 20 \mathrm{~mm}$ day $^{-1}$ shifted well to the east and very weak westerly IVT vectors and IWV $<15 \mathrm{~mm}$ over most of the SCUS (Figs. 11a,d). The SD-composite 298-K isentropic flow advects dry air from the west-southwest across the region, while the ELD composite shows more southerly isentropic flow, suggesting a sustained Gulf connection advecting moister air into the SCUS' eastern region (Figs. 11b,e).

\section{Trajectory analysis}

McCray et al. (2020) suggested that differences in the source regions of air parcels that form the warm layer may be key to distinguishing SD and LD events in the SCUS. The analysis presented in section 3 (e.g., Figs. 8b,e) supports this hypothesis. However, Eulerian wind fields do not necessarily provide 
SD onset $+12 \mathrm{~h}$

250-hPa Z (dam), winds $\left(\mathrm{m} \mathrm{s}^{-1}\right)$, u-wind anomalies $\left(\mathrm{m} \mathrm{s}^{-1}\right)$

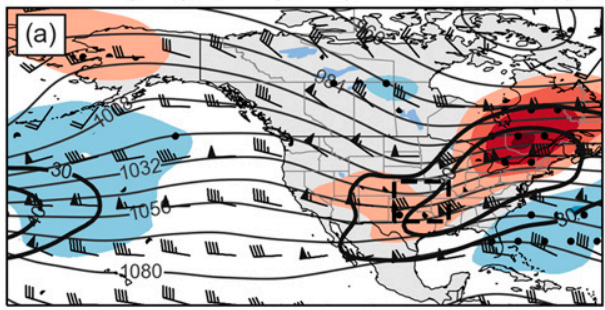

500-hPa Z (dam), Z anomalies (dam), 850-500-hPa $-\nabla$

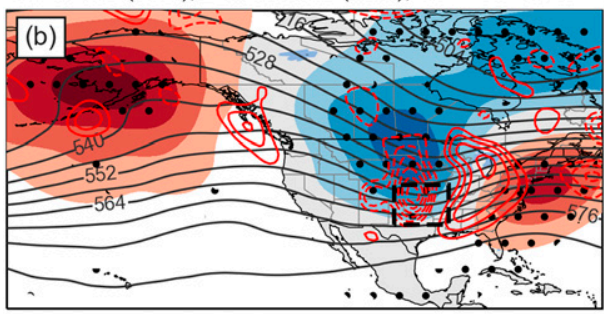

SLP (hPa), SLP anomalies (hPa), 1000-500-hPa thickness (dam)

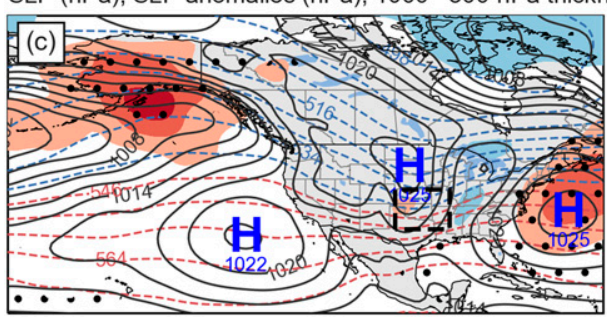

ELD onset $+12 \mathrm{~h}$

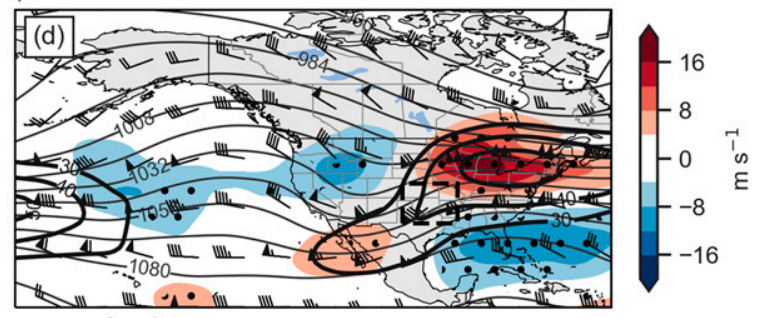

$\mathbf{Q}\left(\mathrm{K} \mathrm{m}^{-2} \mathrm{~s}^{-1}\right)$
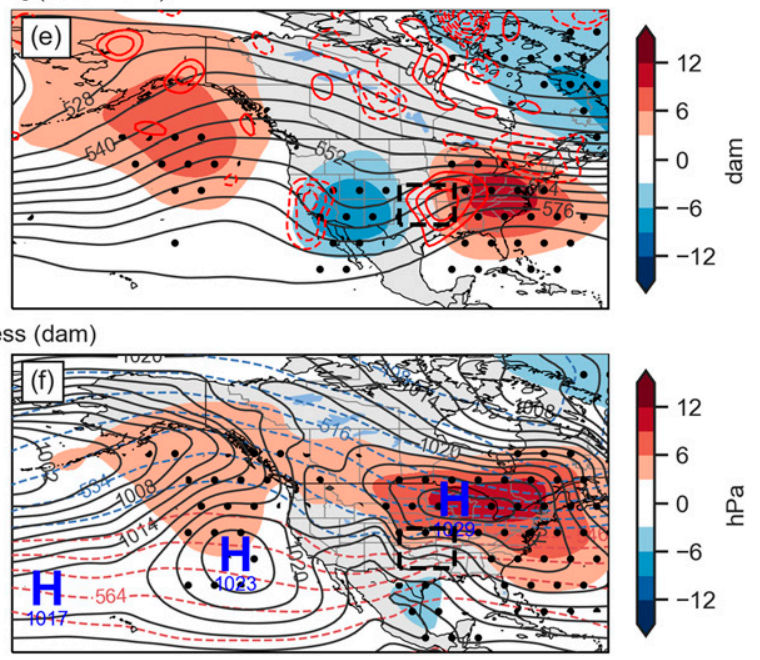

FIG. 9. As in Fig. 3, but at $12 \mathrm{~h}$ after event onset.

information about the Lagrangian history of air parcels, particularly for the more transient SD cases. Therefore, we examine this parcel history through an analysis of 7-day backward trajectories ending at the levels of the warm and cold layers for each of the composited 43 SD and 42 ELD cases.

To illustrate representative warm- and cold-layer trajectories, a random sample of 10 trajectories of each for the 13 January 2007 ELD event is shown in Fig. 12. During the 7 days preceding onset, parcels ending in the warm layer follow two primary trajectories (Fig. 12a). The first path involves parcels descending southeastward across the central United States before reaching the marine PBL and looping anticyclonically over the Gulf of Mexico (Fig. 12a). Parcels warm and moisten during this time, resulting in $\theta_{e}$ values increasing from $\approx 300$ to $\approx 330 \mathrm{~K}$ over a 2 -day period (Fig. 12b). Parcels continue their anticyclonic motion northward, eventually ascending up to the level of the warm layer. The second pathway involves parcels arriving from the eastern Pacific, containing parcels that already have $\theta_{e}$ values of $\approx 330 \mathrm{~K}$ at the beginning of the 7-day period that remain between 600 and $800 \mathrm{hPa}$ throughout the period. These parcels eventually form the upper portion of the warm layer. The parcels ending in the cold layer originate in the low levels over the Arctic (Fig. 12c) and remain cold and dry throughout the 7-day period (Fig. 12d). Both the warm- and cold-layer trajectories strongly resemble those identified by Mullens et al. (2016a) for their January 2010 case.

\section{a. Properties of cold-layer level trajectories}

To gain a more systematic understanding of differences between the source regions of air parcels ending at the warm and cold-layer levels for SD and ELD events, we calculate the spatial density of trajectories among all events of each category at several times preceding onset. We perform this calculation on a $1^{\circ} \times 1^{\circ}$ grid and then divide by the area $\left(\mathrm{km}^{2}\right)$ of each grid box.

First, parcels ending in the cold layer follow a very similar pathway for both SD and ELD events (Fig. 13), with a coherent pattern of trajectories originating over northwestern Canada between 5 and 7 days prior to onset (not shown). Cold layers during SD and ELD events are thus comprising air with Arctic origins, in agreement with the role of the Arctic anticyclone found for both categories in section 3 and prior studies of freezing rain events in this region (Sanders et al. 2013; Mullens 2014; Mullens et al. 2016b). The properties of these cold-layer parcels (not shown) are also nearly identical between the SD and ELD trajectories. As expected from their Arctic origins, these parcels are cold and dry, with median temperatures $\approx 255 \mathrm{~K}$ and water vapor mixing ratios of $\approx 0.5-1 \mathrm{~g} \mathrm{~kg}^{-1}$ before warming and moistening slightly in the three days prior to onset.

\section{b. Properties of warm-layer level trajectories}

While cold-layer trajectory properties for SD and ELD events are nearly identical, warm-layer trajectory properties 

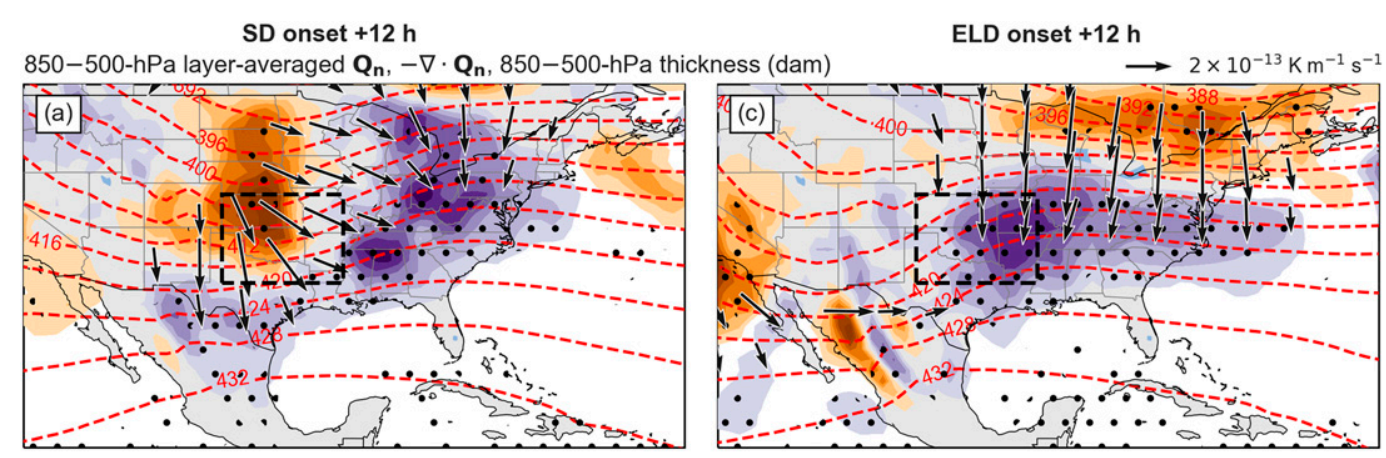

850-500-hPa layer-averaged $\mathbf{Q}_{\mathbf{s}},-\nabla \cdot \mathbf{Q}_{\mathbf{s}}, 850-500-\mathrm{hPa}$ thickness (dam)

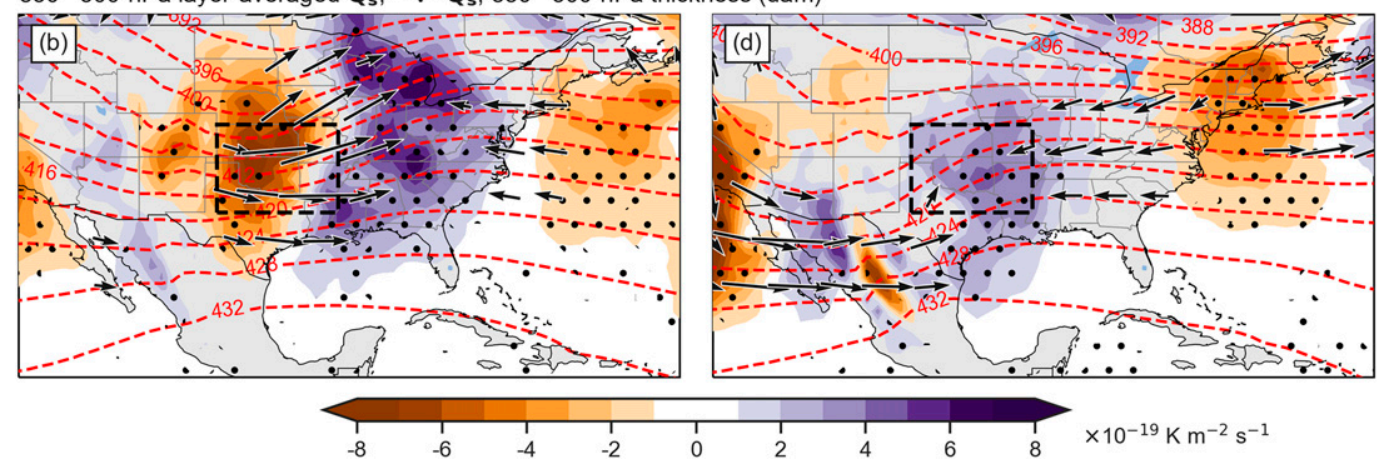

FIG. 10. As in Fig. 7, but at $12 \mathrm{~h}$ after event onset.

differ. At 7 days preceding onset, SD warm-layer parcels begin at slightly higher altitudes than the ELD parcels (Figs. 14a,d). During the -7- to -1-day period, both SD and ELD trajectories descend and warm (Figs. 14a,b). Median $\theta$ values are nearly steady for most of this period, suggesting much of the warming is attributable to adiabatic compression.

A strong signal in the warm-layer trajectory density patterns appears at $72 \mathrm{~h}$ prior to onset (Figs. 13a,f). Although both SD and ELD warm-layer trajectories are predominantly positioned over the Gulf of Mexico, the ELD trajectories are broadly positioned over the open waters (Fig. 13f) while the SD trajectories are confined primarily along the Mexican coast (Fig. 13a). A substantial proportion of both SD and ELD warm-layer trajectories descend below $1 \mathrm{~km}$ above ground level (AGL) by this time (Fig. 14d), though the ELD parcels are preferentially closer to the surface than the SD parcels (median altitudes of $931 \mathrm{~m}$ AGL and $1106 \mathrm{~m}$ AGL, respectively). Median mixing ratios begin to increase for both categories, but more rapidly for the ELD cases (Fig. 14e). Associated with this moistening is an increase in $\theta_{e}$ that is less pronounced for the SD trajectories than in the ELD trajectories (Fig. 14f).

By $36 \mathrm{~h}$ prior to onset, the SD warm-layer parcels show two frequency maxima: one along the east coast of Mexico and another to the west over the Gulf of California (Fig. 13c). The ELD parcels are more concentrated over the Gulf of Mexico, with a much weaker signal to the west (Fig. 13h). These differences suggest the parcels that form the warm layer in the ELD cases reside longer in the marine PBL over the Gulf of Mexico than do the SD trajectories. At $36 \mathrm{~h}$ prior to onset, $61 \%$ of SD parcels are located at pressure levels $<850 \mathrm{hPa}$ compared with only $47 \%$ of ELD parcels. Consequently, the ELD parcels are moister, with a median mixing ratio $\left(\theta_{e}\right)$ of $5.9 \mathrm{~g} \mathrm{~kg}^{-1}(318 \mathrm{~K})$ compared with $4.1 \mathrm{~g} \mathrm{~kg}^{-1}$ (314 K) for SD parcels (Figs. 14e,f).

During the $36 \mathrm{~h}$ prior to onset, parcels ascend northward as they approach the SCUS (Figs. 14a,d). This ascent is nearly isentropic (Figs. 14b,c). During the final $24 \mathrm{~h}$ preceding onset, the median SD (ELD) warm-layer trajectory ascends $210 \mathrm{~m}$ $(551 \mathrm{~m})$ and cools $3.5^{\circ} \mathrm{C}\left(6.0^{\circ} \mathrm{C}\right)$, with a median temperature change per kilometer of ascent of $-8.8^{\circ} \mathrm{C}\left(-8.9^{\circ} \mathrm{C}\right) \mathrm{km}^{-1}$. Particularly in the ELD cases, mixing ratio and $\theta_{e}$ decrease during the final 12-24 h before onset (Figs. 14e,f). Both SD and ELD parcels at $24 \mathrm{~h}$ prior to onset are primarily positioned along the Texas coast, though SD parcels maintain a secondary inland maximum over Mexico whereas ELD parcels are more prominent over the open waters (Figs. 13d,i). The parcels then progress northward, reaching the SCUS region during the $12 \mathrm{~h}$ prior to onset (Figs. 13e, j).

McCray et al. (2020) found that LD events in the SCUS are associated at onset with warmer/deeper warm layers and deeper cloud layers. Here, the largest difference in warm-layer properties appears to be moisture-related, owing to the ELD parcels' additional residence time in the marine PBL over the Gulf of Mexico compared with the SD parcels. Parcels ending in the SD warm layer more often originate to the southwest over the Pacific and track over Mexico before reaching the SCUS. These parcels, lacking recent history over the warm, moist marine PBL, are comparatively drier.

Comparison between the upper and lower portions of the warm layer (not shown) show that the differences evident in 
SD onset $+12 \mathrm{~h}$

IVT $\left(\mathrm{kg} \mathrm{m}^{-1} \mathrm{~s}^{-1}\right), \operatorname{MFC}(\mathrm{mm}), \operatorname{IWV}(\mathrm{mm})$

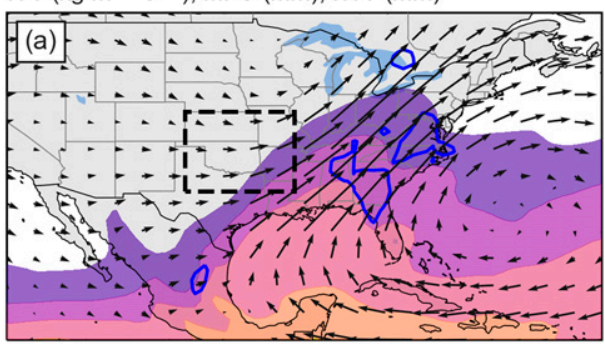

298-K pressure $(\mathrm{hPa})$, winds $\left(\mathrm{m} \mathrm{s}^{-1}\right)$, mixing ratio $\left(\mathrm{g} \mathrm{kg}^{-1}\right)$

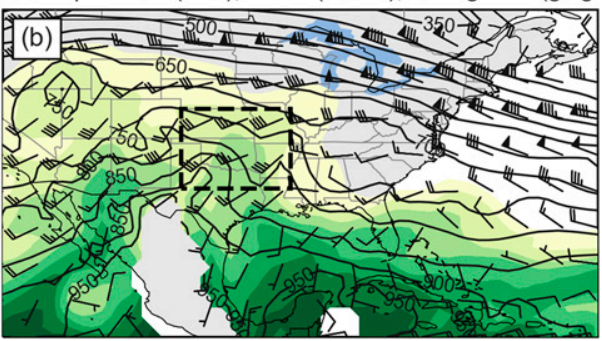

$\mathrm{SLP}(\mathrm{hPa}), 2-\mathrm{m} \theta(\mathrm{K}), 10-\mathrm{m}$ winds $\left(\mathrm{m} \mathrm{s}^{-1}\right)$, sfc. frontogenesis $\left[\mathrm{K}(100 \mathrm{~km})^{-1}(3 \mathrm{~h})^{-1}\right]$

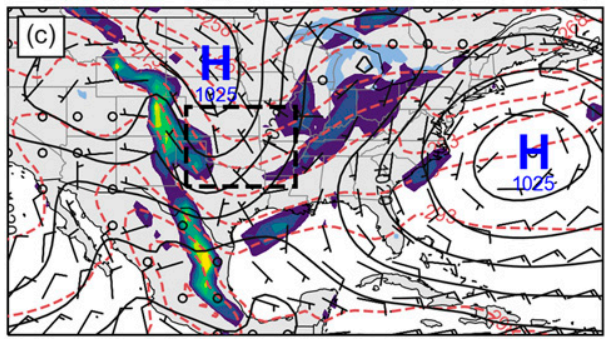

ELD onset $+12 \mathrm{~h}$
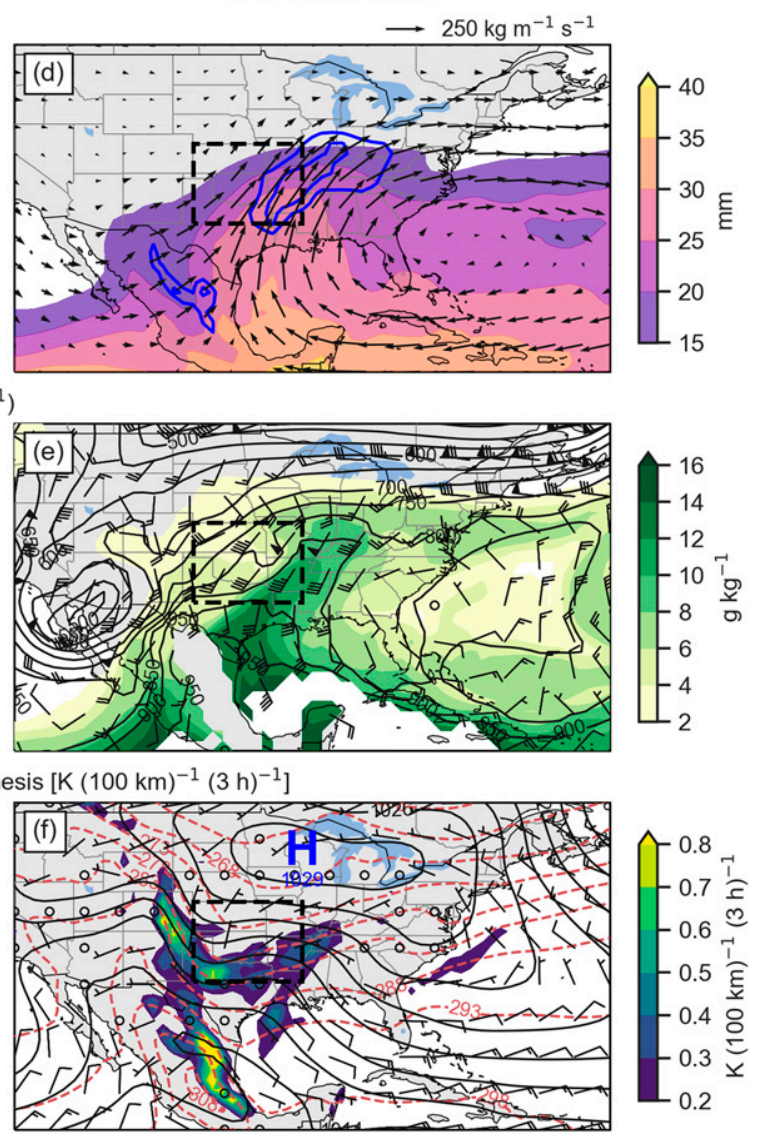

FIG. 11. As in Fig. 8, but at $12 \mathrm{~h}$ after event onset.

Fig. 14 are most pronounced in this layer's upper region. For example, parcels ending at $850 \mathrm{hPa}$ in both the SD and ELD cases share very similar properties and spend the final three days prior to onset near the surface. Conversely, the ELD trajectories ending at $750 \mathrm{hPa}$ generally track closer to the marine PBL than the SD trajectories ending at this level.

\section{c. Trajectories at $12 \mathrm{~h}$ after onset}

In addition to the differences identified in onset characteristics between SD and ELD cases in the SCUS, the rapid passage of the SD longwave trough and relative stationarity of the ELD trough described in section 3 suggest substantial differences in the airmass properties over the SCUS following event onset. To confirm this, we examine backward trajectories ending at the warm- and cold-layer levels at $12 \mathrm{~h}$ after event onset. Because many SD cases will have ended by this point, we remove the $0^{\circ} \mathrm{C}$ criteria and instead identify warm-layer level trajectories as simply those ending in the 900-700-hPa layer and cold-layer level trajectories as those that end within $100 \mathrm{hPa}$ of the surface.

The near-surface trajectories ending $12 \mathrm{~h}$ after SD and ELD onset are both similar to each other and to the cold-layer trajectories at SD and ELD event onset (not shown). In both cases, these trajectories originate to the north, consistent with the composite northerly surface winds maintained $12 \mathrm{~h}$ after both SD and ELD onset (Figs. 11c,f). Though the origins of the parcels ending in the SCUS at onset $+12 \mathrm{~h}$ are more variable than those ending at onset, cold-layer level parcels are most commonly to the north of the SCUS during the final $24 \mathrm{~h}$ of their history (Fig. 15).

Trajectories ending at the warm-layer level $12 \mathrm{~h}$ after SD and ELD onset are, however, quite different from each other. First, $24 \mathrm{~h}$ prior to their arrival in the SCUS box, the SD trajectories most commonly track over the Rockies and northern plains (Fig. 15a), while the ELD trajectories are to the south over Texas and the Gulf of Mexico (Fig. 15b). The ELD parcel positions resemble those at $24 \mathrm{~h}$ prior to ELD onset (Fig. 13i), consistent with the stationary longwave trough found for these events. Consequently, the ELD trajectories are substantially warmer and moister than the SD trajectories (Fig. 16) and strongly resemble the warm-layer trajectories at onset in Fig. 14. For example, at $24 \mathrm{~h}$ prior to reaching the SCUS, the SD (ELD) warm-layer level trajectories ending $12 \mathrm{~h}$ after onset have a median temperature of $269 \mathrm{~K}(280 \mathrm{~K})$ and $\theta_{e}$ of $298 \mathrm{~K}$ (311 K) (Figs. 16b,f).

The trajectory analysis presented in this section highlights several differences between SD and ELD events. First, trajectories ending in the warm layer at ELD event onset are 
(a) Warm layer traj. $p$ (2007-01-13 0600 UTC)

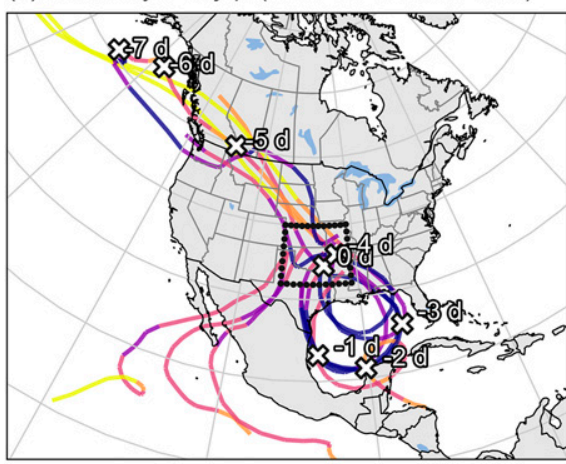

(c) Cold layer traj. $p$ (2007-01-13 0600 UTC)

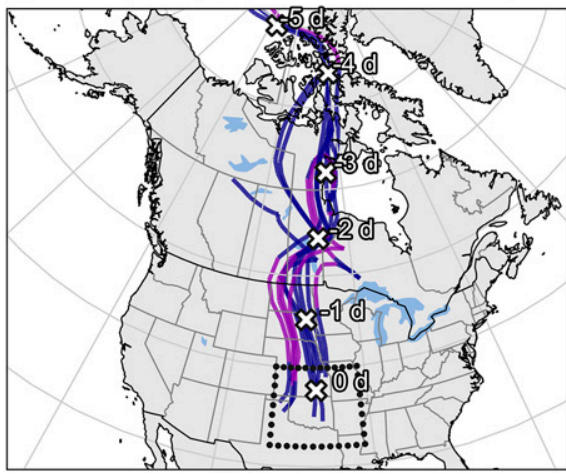

(b) Warm layer traj. $\theta_{e}(2007-01-130600$ UTC)
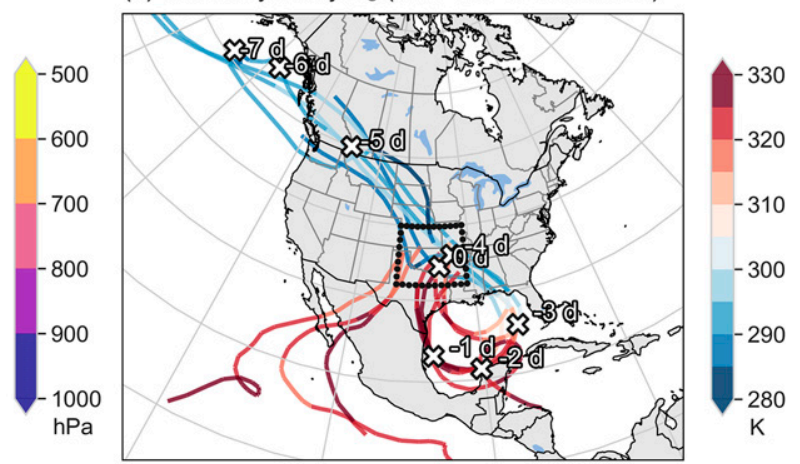

(d) Cold layer traj. $\theta_{e}$ (2007-01-13 0600 UTC)

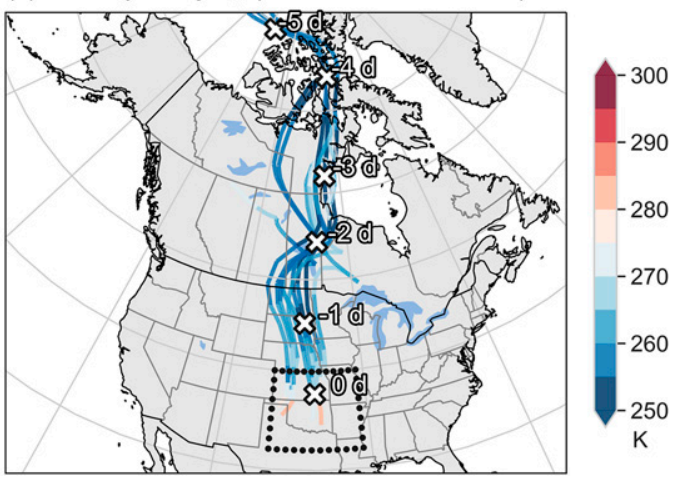

FIG. 12. Examples of (a),(b) 10 randomly selected 7-day backward trajectories ending in the warm layer and (c),(d) 10 ending in the cold layer for the ELD freezing rain case beginning at 0600 UTC 13 Jan 2007. White markers indicate the position of one trajectory in each every $24 \mathrm{~h}$ preceding onset. (a),(c) Pressure levels and (b),(d) equivalent potential temperature $(\mathrm{K})$ of the trajectories are shaded.

primarily distinguished from those at SD event onset by their increased moisture content and $\theta_{e}$. These differences are most pronounced for the parcels ending near the top of the warm layer, indicative of a deeper layer of flow from the Gulf of Mexico into the SCUS at ELD event onset. This agrees with the findings from section 3 and those from the observedsounding analysis of McCray et al. (2020), namely that southerly to southeasterly flow is present through the warm layer at the onset of prolonged events compared with more southwesterly, inland flow into the SD warm layer (Figs. 8a-e). Following onset, the $500-\mathrm{hPa}$ trough passage (Fig. 11b) in the $\mathrm{SD}$ cases results in the advection of cold, dry air from the northwest through a deep layer, eroding the warm layer. Conversely, the near-stationary 500-hPa trough in the ELD cases (Fig. 11e) allows for the maintenance of flow of warm, moist air parcels with a history in the marine PBL over the Gulf of Mexico. This flow acts to sustain the warm layer, contributing to prolonged freezing rain.

\section{Conclusions}

Though the south-central United States observes freezing rain less frequently than other regions of North America, this region has experienced several particularly prolonged freezing rain events (McCray et al. 2019). We have compared the synoptic-dynamic features and airmass properties associated with these ELD events and those associated with SD events over this region.

Both SD and ELD events are preceded by anticyclogenesis over northwestern Canada downstream of strong ridging over the east Pacific. Large differences in synoptic-scale dynamical structures leading to the two event types begin to appear $\approx 2$ days prior to event onset, with the ELD composite anticyclone strengthening and traveling southeastward more rapidly than in the SD composite. ELD events are associated with a deep 500-hPa longwave trough which in some cases becomes a cutoff low over the southwestern United States, leading to a split-flow pattern over the central United States. SD events are characterized by a lower-amplitude trough extending much farther northward.

The more amplified, less progressive 500-hPa trough at ELD event onset appears vital to maintaining several key features supporting freezing rain. During SD events, the trough progresses quickly through the SCUS, with CAA rapidly eroding the warm layer following its passage. The ELD pattern maintains a quasi-stationary front at the leading edge of the Arctic anticyclone over the SCUS, unlike in SD cases where the front traverses the region in the $12 \mathrm{~h}$ following onset. The stationarity of the ELD trough also maintains QG forcing for ascent over the SCUS, while in the SD cases coherent QG 

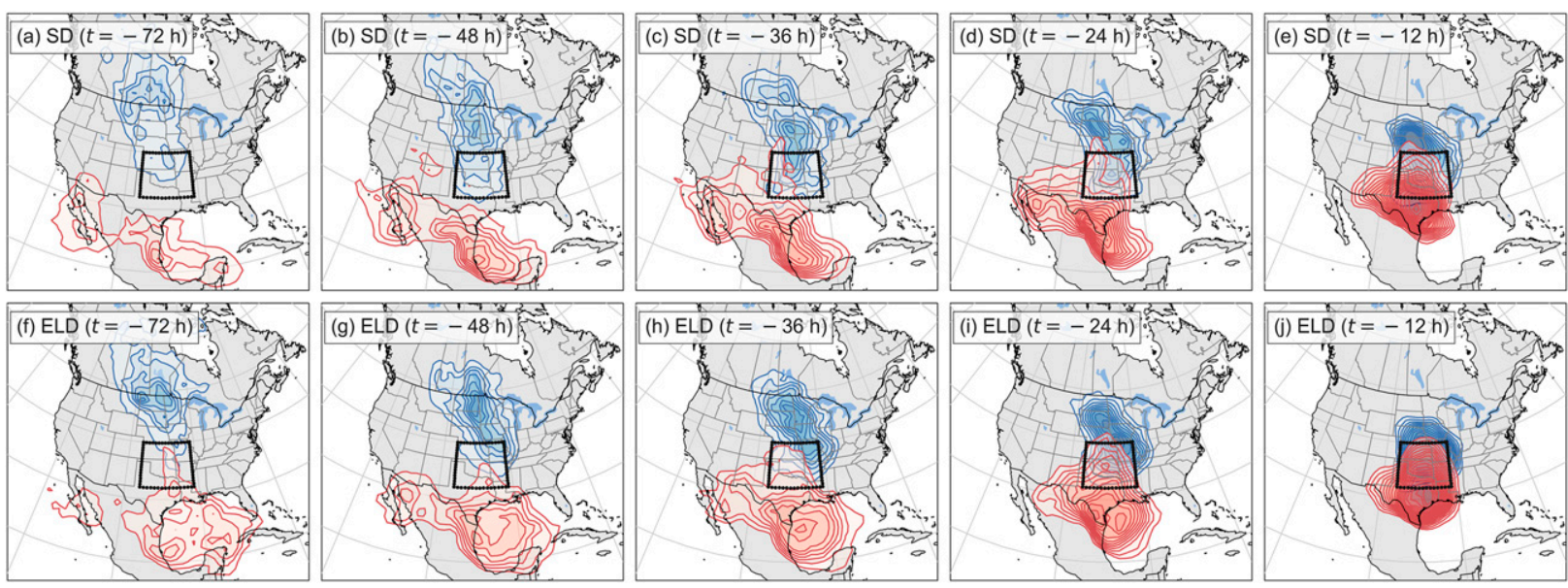

FIG. 13. Density of parcels that end in the warm layer (red) and cold layer (blue) at (top) SD and (bottom) ELD event onset. Shading and contours are plotted for grid points with densities $\geq 0.1 \%(100 \mathrm{~km})^{-2}$, with contours every $0.1 \%(100 \mathrm{~km})^{-2}$ for the cold-layer parcels and every $0.05 \%(100 \mathrm{~km})^{-2}$ for the warm-layer parcels.

forcing for descent occurs by $12 \mathrm{~h}$ after onset. The orientation of the ELD trough also preferentially sustains larger amounts of vertically integrated water vapor and moisture flux convergence over the SCUS at ELD onset and thereafter compared with SD cases.

The high frequency of ELD freezing rain events in the SCUS relative to the other regions examined in McCray et al. (2019) is likely a result of the stationarity of the atmospheric features leading to these events. While the northeastern United States/southeastern Canada (NEUS/SECA) region experiences freezing rain more frequently than the SCUS, freezing rain events in the NEUS/SECA are typically associated with more progressive shortwave troughs (e.g., Ressler et al. 2012; Castellano 2012). Ressler et al. (2012) found that the longestduration freezing rain events at Montreal, Quebec (CYUL) were associated with a 500-hPa height pattern resembling that shown here for SCUS ELD events. However, this pattern was the rarest among the three patterns they identified as responsible for long-duration freezing rain events at CYUL.

Our backward trajectory analysis supports the findings of McCray et al. (2020) that cold layers are very similar for freezing rain events of all durations in the SCUS. Cold-layer parcels for both categories track southward from the Canadian Arctic in the week prior to event onset. In the warm layer, both

Warm layer trajectories ending at 900-700 hPa (SD n=73807 / ELD n=77952)

(a) Pressure $(\mathrm{hPa})$

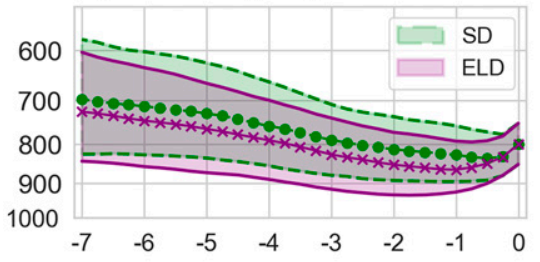

(d) Height AGL (m)

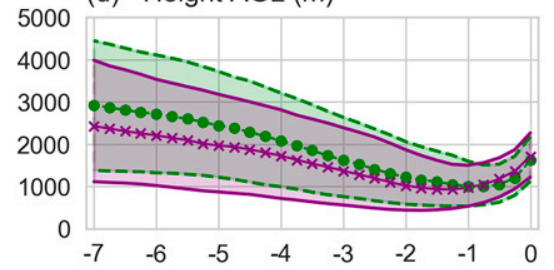

(b) Temperature $(\mathrm{K})$

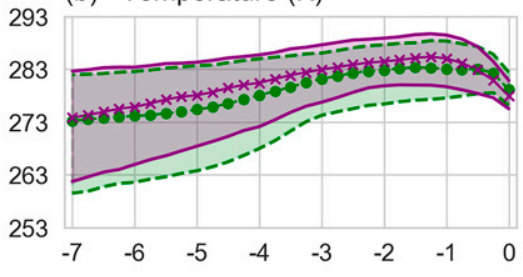

(e) Mixing ratio $\left(\mathrm{g} \mathrm{kg}^{-1}\right)$

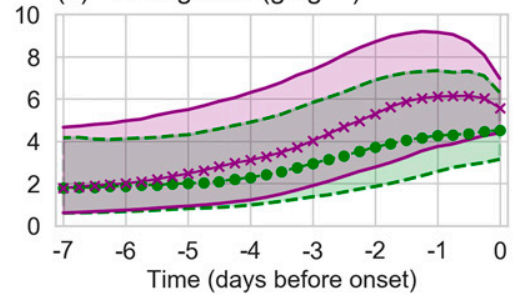

(c) Potential temperature $\theta(\mathrm{K})$

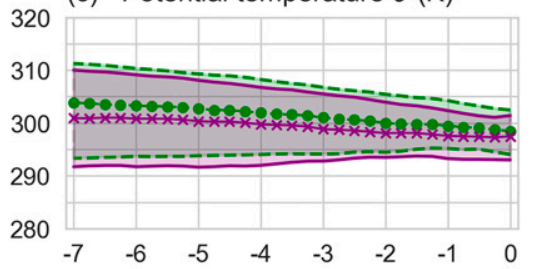

(f) Equivalent pot. temp. $\theta_{e}(\mathrm{~K})$

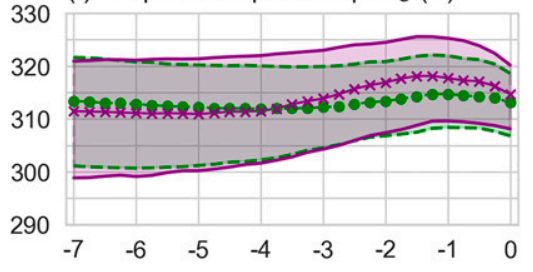

FIG. 14. Airmass properties for 7-day backward trajectories calculated every $6 \mathrm{~h}$ for warm-layer parcels (parcels ending between 900 and $700 \mathrm{hPa}$, at least $50 \mathrm{hPa}$ above the surface, and with temperatures $>0^{\circ} \mathrm{C}$ ) at SD and ELD onset. Median values for ELD trajectories are displayed as solid purple lines and $\times$ markers and green dashed lines and points for SD trajectories, and the 25th-75th percentiles of each field shaded. (a) Parcel pressure (hPa), (b) temperature (K), (c) potential temperature (K), (d) height above ground level (AGL, m), (e) mixing ratio $\left(\mathrm{g} \mathrm{kg}^{-1}\right)$, and (f) equivalent potential temperature $(\mathrm{K})$. 

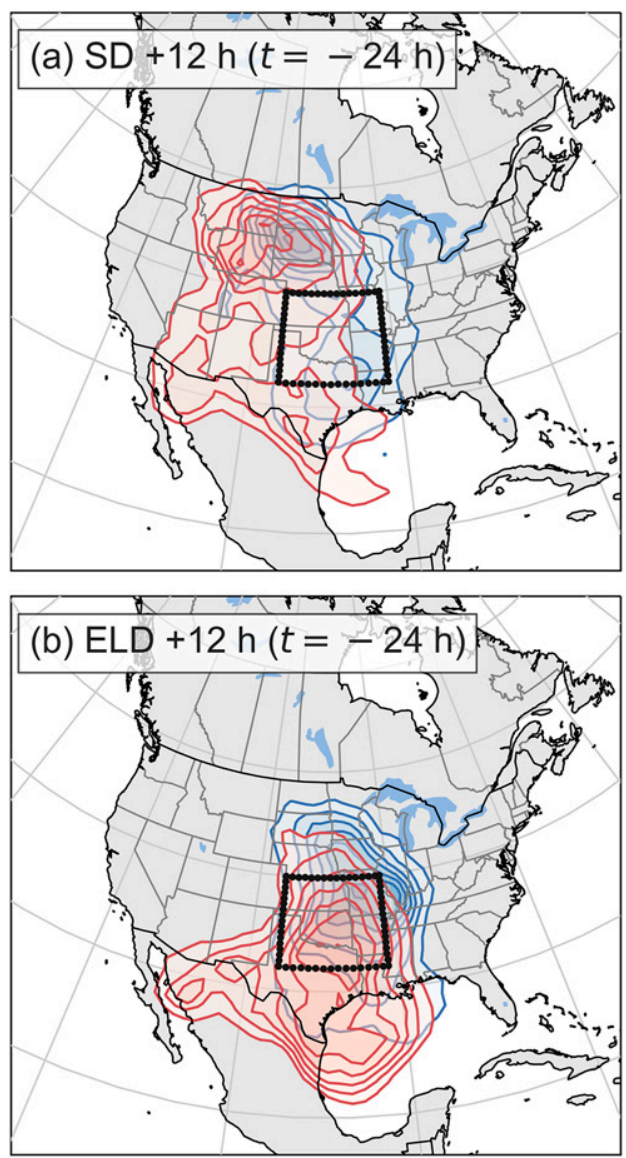

FIG. 15. As in Fig. 13, but for parcels ending in the warm and cold layers at $12 \mathrm{~h}$ after median event onset.

types of events are associated with trajectories with pathways over the Gulf of Mexico. However, ELD cases are associated with a deeper layer of flow with a more prolonged presence over the Gulf, with warming and moistening of these parcels driven by sensible and latent heating in the marine PBL. SD events have a larger proportion of drier warm-layer trajectories originating aloft to the southwest of the region and tracking over Mexico. These differences are most pronounced at the top of the warm layer. By $12 \mathrm{~h}$ after SD event onset, warm-layer level parcels are cold and dry, and track northwest to southeast following the passage of the $500-\mathrm{hPa}$ trough. This is in stark contrast to the ELD cases, in which the stationary longwave trough supports sustained flow of warm, moist parcels from over the Gulf of Mexico northward into the warm layer.

Past studies of severe freezing rain cases in several North American regions have noted the importance of warm sea surface temperatures (SSTs) and trajectories with a history in the marine PBL during these events, including Ramos da Silva et al. (2006) for ice storms in the southeastern United States and Fuhrmann and Konrad (2013) for events in North Carolina. Mullens et al. (2016a) performed a modeling study and found that as Gulf of Mexico SST increased, warm layers were deeper and more persistent during freezing rain events in the U.S. southern Great Plains, generally leading to increased freezing rain.

The importance of these marine trajectories also highlights the sensitivity of the severity of freezing rain events to relatively small variations in the low-level flow fields (e.g., Figs. $8 \mathrm{~b}, \mathrm{e})$. These variations and the associated differences in parcel trajectories over the SCUS can modulate the strength of the warm layer and the moisture profile aloft, thus impacting whether a freezing rain event will be prolonged or brief. Such sensitivity was explored by Roebber and Bosart (1998), who found that differences in low-level flow orientation in the vicinity of the Gulf of Mexico region resulted in very different precipitation distributions under very similar surface and 500-hPa height fields. Gyakum and Roebber (2001) performed a similar analysis for the January 1998 ice storm that resulted in over $100 \mathrm{~mm}$ of ice accretion in southern Quebec and also attributed the extreme nature of this storm relative to analog cases to the more prolonged parcel residence time in the marine PBL.

The relatively coarse ERA-Interim grid spacing and temporal resolution are potential sources of error in our trajectory analysis. In particular, biases in the near-surface temperature and wind fields may result in erroneous identification of cold-layer trajectories. The large agreement between our trajectories and those examined in Mullens et al. (2016a) lends confidence to our findings. Mullens et al. (2016a) calculated 4-day backward trajectories for a case identified here as an ELD event (28-30 January 2010) using 3-hourly output from a 3.3-km Weather Research and Forecasting (WRF) Model (Skamarock et al. 2008) simulation. They identified cold- and warm-layer trajectories that closely resemble the paths we have identified for ELD events (see Fig. 13 in Mullens et al. 2016a). Still, additional analysis of trajectories using reanalysis datasets such as ERA5 (Hersbach et al. 2020) with finer horizontal and vertical grid spacing would help to increase confidence in these results. Additionally, application of the 10-member ERA5 ensemble data would allow for a detailed quantification of the uncertainties associated with analysis errors in our trajectory calculations.

Our diagnostic analysis highlights differences between weak and severe freezing rain events that may assist in pattern recognition for forecasters in the SCUS. While beyond the scope of this paper, additional process-oriented analysis would help confirm these findings and establish causality between synoptic-scale patterns and warm- and cold-layer characteristics. For example, ensemble sensitivity analysis (Ancell and Hakim 2007; Torn and Hakim 2008) could be used to relate the intensity of the antecedent southwestern U.S. trough to the downstream SCUS warm layer aloft and the availability of moisture. Similarly, a modeling study employing potential vorticity inversion (Davis 1992) could be undertaken to modify trough characteristics and identify resultant changes to the warm layer and freezing rain event duration.

Our results expand on those of several past studies on freezing rain events in and around the SCUS region. The ELD pattern identified here closely resembles that identified by Sanders et al. (2013) and Mullens et al. (2016b) for ice storms 
Warm layer level trajectories ending at $900-700 \mathrm{hPa} 12 \mathrm{~h}$ after onset (SD n=132523 / ELD n=129349)

(a) Pressure $(\mathrm{hPa})$

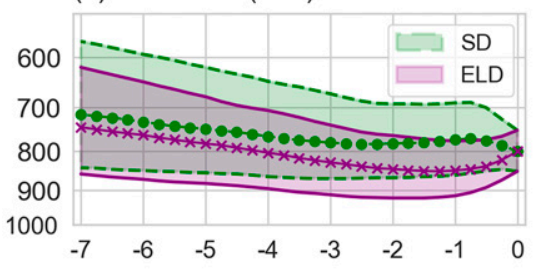

(d) Height AGL (m)

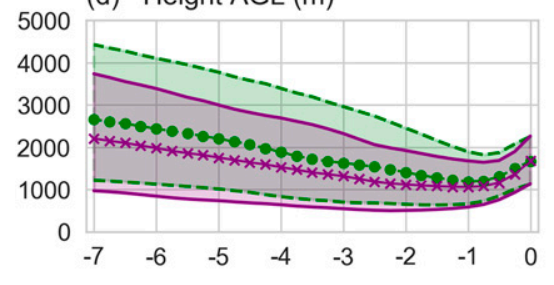

(b) Temperature $(\mathrm{K})$

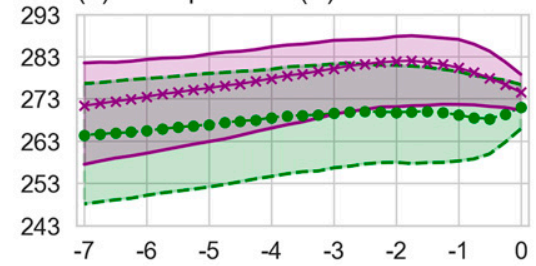

(e) Mixing ratio $\left(\mathrm{g} \mathrm{kg}^{-1}\right)$

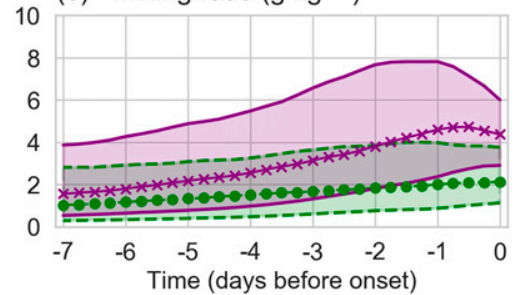

(c) Potential temperature $\theta(\mathrm{K})$

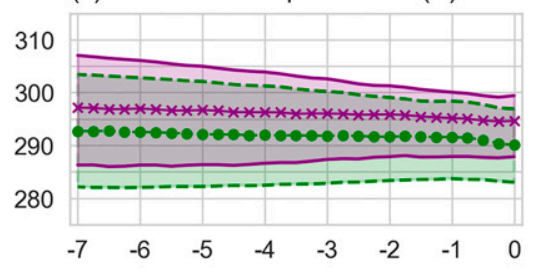

(f) Equivalent pot. temp. $\theta_{e}(\mathrm{~K})$

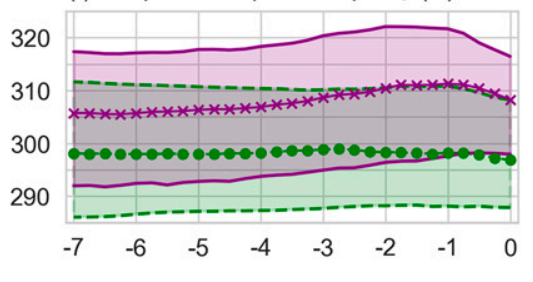

FIG. 16. As in Fig. 14, but only for trajectories ending in the 900-700-hPa layer at $12 \mathrm{~h}$ after SD and ELD event onset.

reaching certain ice accretion criteria in this region. This lends additional confidence to the use of event duration as a proxy for severity, and suggests our technique for identifying regionally grouped freezing rain cases may be useful in other regions for comparison of weak and severe events. This type of comparison has historically been complicated by the lack of public observations of less severe freezing rain events with smaller ice accretion totals.

Finally, our results may help guide research on how freezing rain events in the SCUS may change in the context of a warming climate. Projected increases in Gulf of Mexico SST (e.g., Biasutti et al. 2012) could enhance warm layers and therefore the duration of freezing rain events over this region. Moreover, Muñoz et al. (2020) found an increasing frequency of cutoff lows over western North America. In the context of our findings that ELD freezing rain events are associated with deep troughs or cutoff lows over the southwestern United States, this may increase the frequency of extreme freezing rain events in the SCUS. A reduced frequency of $<0^{\circ} \mathrm{C}$ surface temperatures could, however, decrease the frequency of freezing rain. Further study is therefore warranted to identify the relative importance of each of these factors.

Acknowledgments. This work is supported by the Fonds de Recherche du Québec-Nature et technologies (FRQNT) through the first author's doctoral research scholarship as well as a team grant, and by the Natural Sciences and Engineering Research Council of Canada (NSERC), through their Discovery Grant program and via the Canadian Network for Regional Climate and Weather Processes (CNRCWP). Special thanks to Julian Quinting for guidance on the use of LAGRANTO and to Clark Evans and three anonymous reviewers for their insightful comments that helped strengthen this manuscript.

Data availability statement. Raw data from the Integrated Surface Database used to identify events are available at https://www.ncdc.noaa.gov/isd. Derived data supporting our findings are available from the corresponding author upon request.

\section{REFERENCES}

Ancell, B., and G. J. Hakim, 2007: Comparing adjoint- and ensemble-sensitivity analysis with applications to observation targeting. Mon. Wea. Rev., 135, 4117-4134, https://doi.org/ 10.1175/2007MWR1904.1.

Andrei, S., B. Antonescu, M. Boldeanu, L. Mărmureanu, C. A. Marin, J. Vasilescu, and D. Ene, 2019: An exceptional case of freezing rain in bucharest (Romania). Atmosphere, 10, 673, https://doi.org/10.3390/atmos10110673.

Banacos, P. C., and D. M. Schultz, 2005: The use of moisture flux convergence in forecasting convective initiation: Historical and operational perspectives. Wea. Forecasting, 20, 351-366, https://doi.org/10.1175/WAF858.1.

Bernstein, B. C., 2000: Regional and local influences on freezing drizzle, freezing rain, and ice pellet events. Wea. Forecasting, 15, 485-508, https://doi.org/10.1175/1520-0434(2000)015<0485: RALIOF $>2.0 . \mathrm{CO} ; 2$.

Biasutti, M., A. H. Sobel, S. J. Camargo, and T. T. Creyts, 2012: Projected changes in the physical climate of the Gulf Coast and Caribbean. Climatic Change, 112, 819-845, https://doi.org/ 10.1007/s10584-011-0254-y.

Brooks, C. F., 1920: The nature of sleet and how it is formed. Mon. Wea. Rev., 48, 69-72, https://doi.org/10.1175/1520-0493(1920) $48<69$ b:TNOSAH $>2.0$.CO;2.

Castellano, C. M., 2012: Synoptic and mesoscale aspects of ice storms in the northeastern U.S. M.S. thesis, Dept. of Atmospheric and Environmental Sciences, University at Albany, State University of New York, 149 pp.

Changnon, S. A., 2003: Characteristics of ice storms in the United States. J. Appl. Meteor., 42, 630-639, https://doi.org/10.1175/ 1520-0450(2003)042<0630:COISIT >2.0.CO;2.

Cortinas, J. V., B. C. Bernstein, C. C. Robbins, and J. W. Strapp, 2004: An analysis of freezing rain, freezing drizzle, and ice pellets across the United States and Canada: 197690. Wea. Forecasting, 19, 377-390, https://doi.org/10.1175/ 1520-0434(2004)019<0377:AAOFRF $>2.0$.CO;2. 
Davis, C. A., 1992: Piecewise potential vorticity inversion. J. Atmos. Sci., 49, 1397-1411, https://doi.org/10.1175/1520-0469(1992) $049<1397:$ PPVI $>2.0$. CO 2 .

Dee, D. P., and Coauthors, 2011: The ERA-Interim reanalysis: Configuration and performance of the data assimilation system. Quart. J. Roy. Meteor. Soc., 137, 553-597, https://doi.org/ 10.1002/qj.828.

Fuhrmann, C. M., and C. E. Konrad, 2013: A trajectory approach to analyzing the ingredients associated with heavy winter storms in central North Carolina. Wea. Forecasting, 28, 647-667, https://doi.org/10.1175/WAF-D-12-00079.1.

Gyakum, J. R., and P. J. Roebber, 2001: The 1998 ice stormAnalysis of a planetary-scale event. Mon. Wea. Rev., 129, 2983-2997, https://doi.org/10.1175/1520-0493(2001)129<2983: TISAOA $>2.0 . \mathrm{CO} ; 2$.

Hersbach, H., and Coauthors, 2020: The ERA5 global reanalysis. Quart. J. Roy. Meteor. Soc., 146, 1999-2049, https://doi.org/ 10.1002/qj.3803.

Hoskins, B. J., I. Draghici, and H. C. Davies, 1978: A new look at the $\omega$-equation. Quart. J. Roy. Meteor. Soc., 104, 31-38, https:// doi.org/10.1002/qj.49710443903.

Huffman, G. J., and G. A. Norman, 1988: The supercooled warm rain process and the specification of freezing precipitation. Mon. Wea. Rev., 116, 2172-2182, https://doi.org/10.1175/15200493(1988)116<2172:TSWRPA > 2.0.CO;2.

Keyser, D., M. J. Reeder, and R. J. Reed, 1988: A generalization of Petterssen's frontogenesis function and its relation to the forcing of vertical motion. Mon. Wea. Rev., 116, 762-781, https://doi.org/10.1175/1520-0493(1988)116<0762:AGOPFF> 2.0.CO;2.

McCray, C. D., E. H. Atallah, and J. R. Gyakum, 2019: Longduration freezing rain events over North America: Regional climatology and thermodynamic evolution. Wea. Forecasting, 34, 665-681, https://doi.org/10.1175/WAF-D-18-0154.1.

_ J. R. Gyakum, and E. H. Atallah, 2020: Regional thermodynamic characteristics distinguishing long- and short-duration freezing rain events over North America. Wea. Forecasting, 35, 657-671, https://doi.org/10.1175/WAF-D-19-0179.1.

Meisinger, C. L., 1920: The precipitation of sleet and the formation of glaze in the eastern United States, January 20 to 25, 1920, with remarks on forecasting. Mon. Wea. Rev., 48, 73-80, https://doi.org/10.1175/1520-0493(1920)48<73b:TPOSAT> 2.0.CO;2.

Milrad, S. M., E. H. Atallah, J. R. Gyakum, and G. Dookhie, 2014: Synoptic typing and precursors of heavy warm-season precipitation events at Montreal, Québec. Wea. Forecasting, 29, 419-444, https://doi.org/10.1175/WAF-D-13-00030.1.

—- J. R. Gyakum, and E. H. Atallah, 2015: A meteorological analysis of the 2013 Alberta flood: Antecedent largescale flow pattern and synoptic-dynamic characteristics. Mon. Wea. Rev., 143, 2817-2841, https://doi.org/10.1175/ MWR-D-14-00236.1.

Mullens, E. D., 2014: Moisture and thermal characteristics of Southern Plains ice storms: Insights from a regional climatology and high-resolution WRF-ARW sensitivity study. Ph.D. thesis, University of Oklahoma, $342 \mathrm{pp}$.

— , L. M. Leslie, and P. J. Lamb, 2016a: Impacts of Gulf of Mexico SST anomalies on southern plains freezing precipitation: ARW sensitivity study of the 28-30 January 2010 winter storm. J. Appl. Meteor. Climatol., 55, 119-143, https://doi.org/ 10.1175/JAMC-D-14-0289.1.

,$- \ldots$, and $-2016 \mathrm{~b}$ : Synoptic pattern analysis and climatology of ice and snowstorms in the southern Great Plains,
1993-2011. Wea. Forecasting, 31, 1109-1136, https://doi.org/ 10.1175/WAF-D-15-0172.1.

Muñoz, C., D. Schultz, and G. Vaughan, 2020: A midlatitude climatology and interannual variability of $200-$ and $500-\mathrm{hPa}$ cutoff lows. J. Climate, 33, 2201-2222, https://doi.org/10.1175/ JCLI-D-19-0497.1.

Neiman, P. J., F. M. Ralph, G. A. Wick, J. D. Lundquist, and M. D. Dettinger, 2008: Meteorological characteristics and overland precipitation impacts of atmospheric rivers affecting the West Coast of North America based on eight years of SSM/I satellite observations. J. Hydrometeor., 9, 22-47, https://doi.org/ 10.1175/2007JHM855.1.

Ramos da Silva, R., G. Bohrer, D. Werth, M. J. Otte, and R. Avissar, 2006: Sensitivity of ice storms in the southeastern United States to Atlantic SST-Insights from a case study of the December 2002 storm. Mon. Wea. Rev., 134, 1454-1464, https://doi.org/10.1175/MWR3127.1.

Rauber, R. M., M. K. Ramamurthy, and A. Tokay, 1994: Synoptic and mesoscale structure of a severe freezing rain event: The St. Valentine's Day ice storm. Wea. Forecasting, 9, 183-208, https://doi.org/10.1175/1520-0434(1994)009<0183:SAMSOA > 2.0.CO;2.

_ L. S. Olthoff, M. K. Ramamurthy, and K. E. Kunkel, 2000: The relative importance of warm rain and melting processes in freezing precipitation events. J. Appl. Meteor., 39, 1185-1195, https://doi.org/10.1175/1520-0450(2000)039<1185:TRIOWR> 2.0.CO;2.

——, - —, D. Miller, and K. E. Kunkel, 2001: A synoptic weather pattern and sounding-based climatology of freezing precipitation in the United States East of the Rocky Mountains. J. Appl. Meteor., 40, 1724-1747, https://doi.org/10.1175/1520-0450(2001)040<1724:ASWPAS $>$ 2.0.CO;2.

Ressler, G. M., S. M. Milrad, E. H. Atallah, and J. R. Gyakum, 2012: Synoptic-scale analysis of freezing rain events in Montreal, Quebec, Canada. Wea. Forecasting, 27, 362-378, https://doi.org/ 10.1175/WAF-D-11-00071.1.

Robbins, C. C., and J. V. Cortinas, 2002: Local and synoptic environments associated with freezing rain in the contiguous United States. Wea. Forecasting, 17, 47-65, https://doi.org/ 10.1175/1520-0434(2002)017<0047:LASEAW>2.0.CO;2.

Roebber, P. J., and L. F. Bosart, 1998: The sensitivity of precipitation to circulation details. Part I: An analysis of regional analogs. Mon. Wea. Rev., 126, 437-455, https://doi.org/10.1175/ 1520-0493(1998)126<0437:TSOPTC >2.0.CO;2.

—_, and J. R. Gyakum, 2003: Orographic influences on the mesoscale structure of the 1998 ice storm. Mon. Wea. Rev., 131, 27-50, https://doi.org/10.1175/1520-0493(2003)131<0027:OIOTMS> 2.0.CO;2.

Ryerson, C. C., and A. C. Ramsay, 2007: Quantitative ice accretion information from the Automated Surface Observing System. J. Appl. Meteor. Climatol., 46, 1423-1437, https://doi.org/ 10.1175/JAM2535.1.

Saha, S., and Coauthors, 2010: The NCEP Climate Forecast System Reanalysis. Bull. Amer. Meteor. Soc., 91, 1015-1058, https:// doi.org/10.1175/2010BAMS3001.1.

Sanders, K., and B. L. Barjenbruch, 2016: Analysis of ice-to-liquid ratios during freezing rain and the development of an ice accumulation model. Wea. Forecasting, 31, 1041-1060, https:// doi.org/10.1175/WAF-D-15-0118.1.

—, C. Gravelle, J. Gagan, and C. Graves, 2013: Characteristics of major ice storms in the central United States. J. Oper. Meteor., 1, 100-113, https://doi.org/10.15191/nwajom.2013.0110. 
Skamarock, W. C., and Coauthors, 2008: A description of the Advanced Research WRF version 3. NCAR Tech. Note NCAR/ TN-475+STR, 113 pp., https://doi.org/10.5065/D68S4MVH.

Smith, A., N. Lott, and R. Vose, 2011: The integrated surface database: Recent developments and partnerships. Bull. Amer. Meteor. Soc., 92, 704-708, https://doi.org/10.1175/2011BAMS3015.1.

Sprenger, M., and H. Wernli, 2015: The LAGRANTO Lagrangian analysis tool-version 2.0. Geosci. Model Dev., 8, 2569-2586, https://doi.org/10.5194/gmd-8-2569-2015.

Torn, R. D., and G. J. Hakim, 2008: Ensemble-based sensitivity analysis. Mon. Wea. Rev., 136, 663-677, https://doi.org/10.1175/ 2007MWR2132.1.
Wasserstein, R. L., and N. A. Lazar, 2016: The ASA statement on p-values: Context, process, and purpose. Amer. Stat., 70, 129-133, https://doi.org/10.1080/00031305.2016.1154108.

Wilks, D. S., 2016: “The stippling shows statistically significant grid points" How research results are routinely overstated and overinterpreted, and what to do about it. Bull. Amer. Meteor. Soc., 97, 2263-2273, https://doi.org/10.1175/BAMS-D15-00267.1.

Zhou, B., and Coauthors, 2011: The Great 2008 Chinese ice storm: Its socioeconomic-ecological impact and sustainability lessons learned. Bull. Amer. Meteor. Soc., 92, 47-60, https://doi.org/ 10.1175/2010BAMS2857.1. 